\title{
Synthesis of pyranicin and its deoxygenated analogues and their inhibitory action with bovine heart mitochondrial complex I
}

Shin-ichi Furuhata, ${ }^{a}$ Yasunao Hattori, ${ }^{\text {b,c }}$ Motonori Okajima, ${ }^{a}$ Hiroyuki Konno, ${ }^{\mathrm{d}}$ Masato, Abe, ${ }^{\mathrm{e}}$ Hideto, Miyoshi, Tetsuhisa Goto, ${ }^{\mathrm{b}, \mathrm{f}}$ and Hidefumi Makabe ${ }^{\mathrm{a} *}$

${ }^{a}$ Sciences of Functional Foods, Graduate School of Agriculture, Shinshu University, 8304 Minami-minowa, Kamiina, Nagano 399-4598, Japan

${ }^{\mathrm{b}}$ Interdisciplinary Graduate School of Science and Technology, Shinshu University, 8304, Minami-minowa, Kami-ina, Nagano, 399-4598, Japan

${ }^{\mathrm{c}}$ Satellite Venture Business Laboratory, Shinshu University, 3-15-1, Tokida, Ueda, Nagano, 386-8567, Japan

${ }^{\mathrm{d}}$ Department of Chemistry, Graduate School of Medical Science, Kyoto Prefectural University of Medicine, Kitaku, Kyoto 603-8334, Japan

${ }^{\mathrm{e} D i v i s i o n}$ of Applied Life Sciences, Graduate School of Agriculture, Kyoto University, Kita-shirakawa, Sakyo-ku, Kyoto 606-8502, Japan

${ }^{\mathrm{f}}$ Department of Bioscience and Biotechnology, Faculty of Agriculture, Shinshu University, 8304, Minami-minowa, Kami-ina, Nagano, 399-4598, Japan

*Corresponding author. Tel. +81 26577 1630; fax +81 26577 1700, e-mail: makabeh@shinshu-u.ac.jp

\begin{abstract}
Total synthesis of pyranicin and its deoxygenated analogues were achieved using $\mathrm{Cl}_{2} \mathrm{Pd}\left(\mathrm{CH}_{3} \mathrm{CN}\right)_{2}$ catalyzed diastereoselective cyclization of the allylic ester as the key step. The inhibitory activity of these compound for mitochondrial NADH-ubiquinone oxidoreductase (complex I) was poorer than those of ordinary mono-THF acetogenins such as annonacin.
\end{abstract}

Key words: annonaceous acetogenin, antitumor, mitochondrial complex I, stereoselective synthesis

\section{Introduction}

The annonaceous acetogenins, which are isolated from a number of tropical plants of Annonaceae, have attracted much attention in recent years due to a wide variety of biological features, including cytotoxic, antitumoral, and antimalarial activities. Their unique structures are characterized by a terminal $\alpha, \beta$-unsaturated $\gamma$-lactone 
ring and a long aliphatic side chain which is connected with various oxygen containing moieties such as THF, THP and/or epoxide rings, and several hydroxy groups on C-35 or C-37 carbon chain. The inhibitory effect of acetogenins on mitochondrial NADH-ubiquinone oxidoreductase (complex I) is of particular importance since their diverse biological activities are thought to be attributable to this effect. Using systematically selected natural and synthetic THF- type acetogenins, Miyoshi and colleagues revealed that the alkyl spacer linking the $\gamma$-lactone and the hydroxylated THF moieties dynamically regulate the binding of these two toxophores to the putative binding sites. ${ }^{1}$ So far, over 430 acetogenins have been isolated from Annonaceae, ${ }^{2-4}$ however, only 8 compounds contain a THP ring. Consequently, significant efforts have been devoted toward synthesis of THP-containing acetogenins due to their unique structures. ${ }^{5}$ Pyranicin (1) is a mono-THP acetogenin, first isolated from the stem bark of Goniothalamus giganteus in 1998 (Figure 1). ${ }^{6}$ In 2003, Takahashi synthesized pyranicin (1) via $\mathrm{SmI}_{2-}$ induced reductive cyclization of $\beta$-alkoxy acrilate. ${ }^{5 f}$ Strand also achieved synthesis of pyranicin (1) using asymmetric Horner-Emmons reaction in $2005 .^{5 c, 5 d}$ To our knowledge, the inhibitory action of THP-type acetogenins has not been characterized at the enzyme level. Pyranicin (1) has a C-13 alkyl spacer whose length is most suitable for the inhibition of complex I in the case of mono- and bis-THF acetogenins. ${ }^{1}$ Thus, it is very important to investigate the role of the THP ring in the inhibitory action. In the previous communication, we reported the total synthesis of pyranicin (1) employing a Pd-catalyzed diastereoselective cyclization strategy, ${ }^{7,8}$ and its inhibitory action with bovine heart complex I. ${ }^{9}$ As for the inhibitory activity, the $\mathrm{IC}_{50}$ of pyranicin was 7.5 $( \pm 0.30) \mathrm{nM}$. This indicated that the inhibitory potency of this compound is slightly, but significantly, lower than that of cis-solamin $\left(\mathrm{IC}_{50} 2.2( \pm 0.18) \mathrm{nM}\right) .{ }^{10}$ Considering the fact that the presence of multiple hydroxy groups in the spacer region is markedly adverse to the inhibition, ${ }^{1 \text { a }}$ the presence of an additional hydroxy group in the 10position may be the cause of the decrease in the inhibitory potency of pyranicin. In order to elucidate the role of the THP ring, we designed deoxygenated pyranicin analogues, 10-deoxypyranicin (2) and 4,10-dideoxypyranicin (3) to make direct comparison with mono-THF acetogenins, annonacin, ${ }^{11}$ murisolin, ${ }^{12}$ and cis-solamin (Figure 1). Herein we wish to report the synthesis of 1, 2, and $\mathbf{3}$ and their inhibitory action with bovine heart mitochondrial complex I (Figure 1).
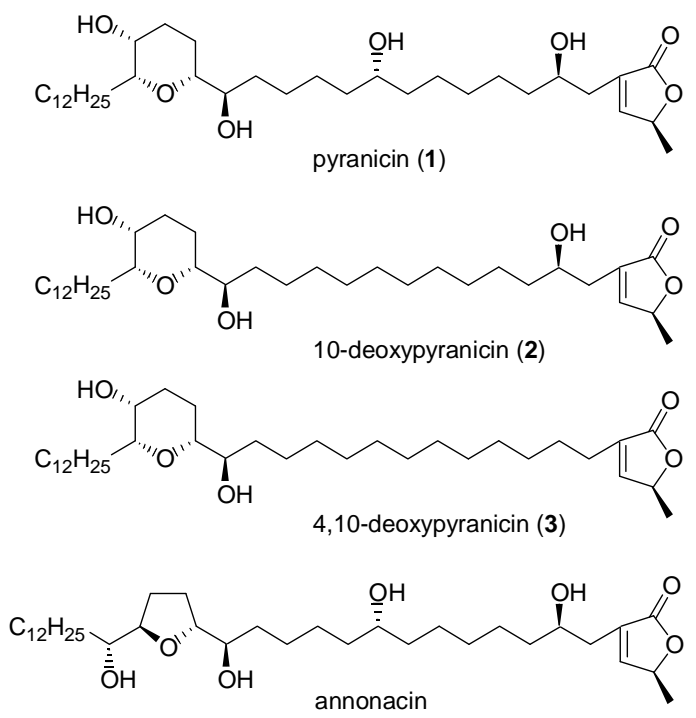


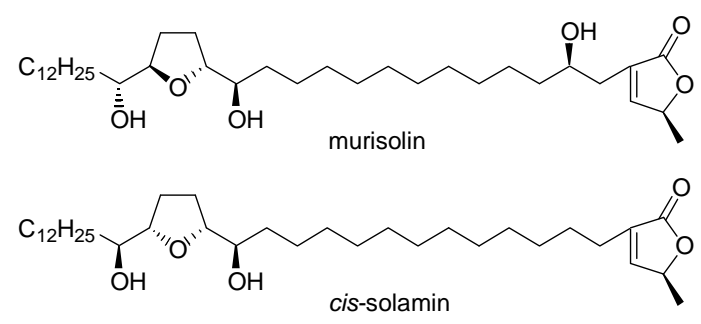

Figure 1. The structures of pyranicin (1) and its deoxygenated analogues, 10-deoxypyranicin (2), 4,10dideoxypyranicin (3), and related mono-THF acetogenins, annonacin, murisolin, and cis-solamin.

\section{Results and Discussion}

\subsection{Synthesis}

Scheme 1 outlines our synthetic strategy of pyranicin (1). The key step is Pd-catalyzed diastereoselective cyclization from $\mathbf{7}$ to $\mathbf{6 a}$. This reaction proceeded in high diastereoselective manner and it would be useful for the synthesis of other THP containing acetogenins. The starting material is (-)-muricatacin (8) which was reported by our group (Scheme 1). ${ }^{13,14}$

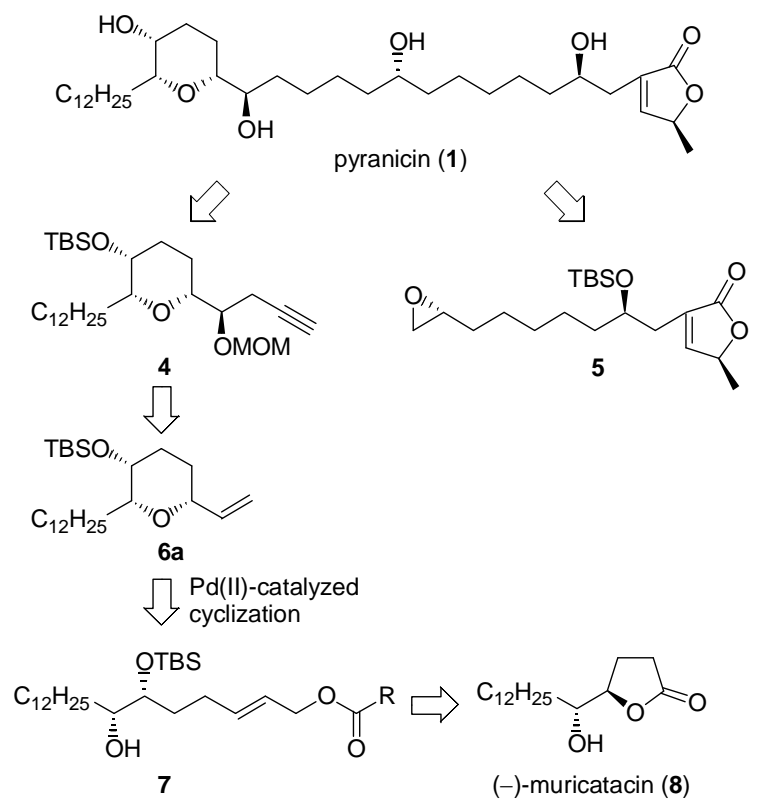

Scheme 1. Retrosynthetic analysis.

As shown in Scheme 2, the key intermediate 7 was constructed as follows. Protection of 8 with ethyl vinyl ether and a catalytic amount of PPTS afforded 9, followed by semi-reduction with DIBALH afforded hemi-acetal and subsequent careful Horner-Emmons reaction at $-50^{\circ} \mathrm{C}$ afforded $\alpha, \beta$-unsaturated ester 10. Protection of the hydroxy group of $\mathbf{1 0}$ with $\mathrm{TBSCl}$ and imidazole to give $\mathbf{1 1}$ and subsequent reduction with DIBALH gave allylic alcohol 12. Esterification of $\mathbf{1 2}$ with various acid chlorides, followed by removal of the ethoxyethyl group with $0.5 \mathrm{~N}$ hydrochloric acid afforded the cyclization precursor 7 (Scheme 2). 


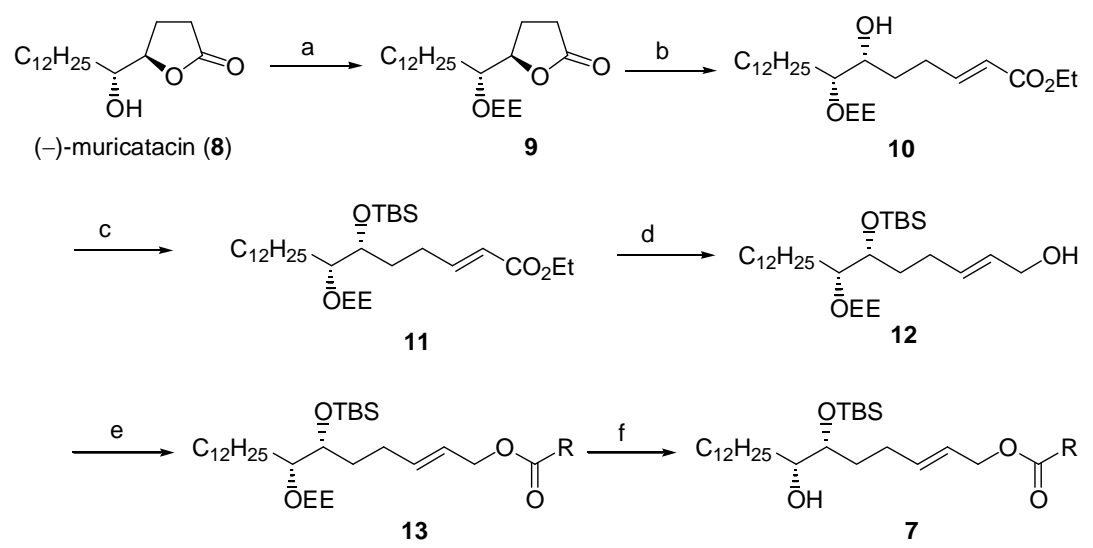

Scheme 2. Preparation of cyclization precursor 7. Reagents and conditions: (a) ethyl vinyl ether, PPTS, $\mathrm{CH}_{2} \mathrm{Cl}_{2}$ (quant.); (b) (i) DIBALH, $\mathrm{CH}_{2} \mathrm{Cl}_{2}$, (ii) (EtO) ${ }_{2} \mathrm{P}(\mathrm{O}) \mathrm{CH}_{2} \mathrm{CO}_{2} \mathrm{Et}, \mathrm{NaH}, \mathrm{THF},-50{ }^{\circ} \mathrm{C}$ (88\%, 2 steps); (c) TBSCl, imidazole, DMF (93\%); (d) DIBALH, $\mathrm{CH}_{2} \mathrm{Cl}_{2}$ (97\%); (e) 3-phenylbenzoylchloride, DMAP, pyridine (96\%); (f) $0.5 \mathrm{~N} \mathrm{HCl}$, THF- $\mathrm{H}_{2} \mathrm{O}(85 \%)$.

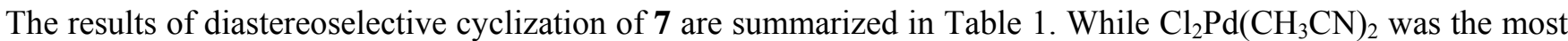
effective catalyst in the diastereoselective cyclization, $\mathrm{PdCl}_{2}$ and $\mathrm{Cl}_{2} \mathrm{Pd}\left(\mathrm{PPh}_{3}\right)_{2}$ were ineffective. One of the reasons for low selectivity and yield in the case of $\mathrm{PdCl}_{2}$ may be due to the low solubility in organic solvent. Because $\mathrm{PdCl}_{2}$ exists as an essentially linear doubly Cl-bridged polymer. ${ }^{15}$ As far as we have found, substituted aromatic esters are appropriate substrates such as 3-phenylbenzoate. As for the solvent, $\mathrm{CH}_{2} \mathrm{Cl}_{2}$ gave a good selectivity although the yield was a little bit lower than DME. A chair-like transition state with an equatorial orientation of all substituents can explain the favorable formation of the desired stereoisomer 6a. Steric requirement such as 3-phenylbenzoyl group might also be necessary to get high selectivity (Table 1, Figure 2).

Table 1. Pd(II)-catalyzed diastereoselective cyclization of allylic esters.

\begin{tabular}{|c|c|c|c|c|c|c|}
\hline 25 & ГBS & ${ }^{R}$ & ID & $6 a$ & $\begin{array}{l}\text { TBSO, } \\
+\quad \mathrm{C}_{12} \mathrm{H}_{25}\end{array}$ & 6b \\
\hline $\mathrm{R}$ & solvent & catalyst & time (h) & $t\left({ }^{\circ} \mathrm{C}\right)$ & yield $(\mathbf{6} \mathbf{a}+\mathbf{6} \mathbf{b}) \%$ & $6 a: 6 b^{a}$ \\
\hline mesityl & DME & $\mathrm{Cl}_{2} \mathrm{Pd}\left(\mathrm{PPh}_{3}\right)_{2}$ & 12 & $\mathrm{rt}$ & - & - \\
\hline mesityl & DME & $\mathrm{PdCl}_{2}$ & 12 & rt & 49 & $78: 22$ \\
\hline mesityl & DME & $\mathrm{Cl}_{2} \mathrm{Pd}\left(\mathrm{CH}_{3} \mathrm{CN}\right)_{2}$ & 12 & rt & 73 & $84: 16$ \\
\hline methyl & DME & $\mathrm{Cl}_{2} \mathrm{Pd}\left(\mathrm{CH}_{3} \mathrm{CN}\right)_{2}$ & 12 & $\mathrm{rt}$ & 78 & $67: 33$ \\
\hline$t$-Bu & DME & $\mathrm{Cl}_{2} \mathrm{Pd}\left(\mathrm{CH}_{3} \mathrm{CN}\right)_{2}$ & 12 & rt & 23 & $81: 19$ \\
\hline phenyl & DME & $\mathrm{Cl}_{2} \mathrm{Pd}\left(\mathrm{CH}_{3} \mathrm{CN}\right)_{2}$ & 12 & $\mathrm{rt}$ & 29 & $83: 17$ \\
\hline biphenyl & DME & $\mathrm{Cl}_{2} \mathrm{Pd}\left(\mathrm{CH}_{3} \mathrm{CN}\right)_{2}$ & 12 & $\mathrm{rt}$ & 99 & $90: 10$ \\
\hline biphenyl & DME & $\mathrm{Cl}_{2} \mathrm{Pd}\left(\mathrm{CH}_{3} \mathrm{CN}\right)_{2}$ & 12 & 0 & N.R. & - \\
\hline biphenyl & $\mathrm{CH}_{2} \mathrm{Cl}_{2}$ & $\mathrm{Cl}_{2} \mathrm{Pd}\left(\mathrm{CH}_{3} \mathrm{CN}\right)_{2}$ & 4 & -10 & 74 & $93: 7$ \\
\hline
\end{tabular}

${ }^{\mathrm{a}}$ The ratio of $\mathbf{6 a}$ and $\mathbf{6} \mathbf{b}$ was determined by ${ }^{1} \mathrm{H}$ NMR analysis. 

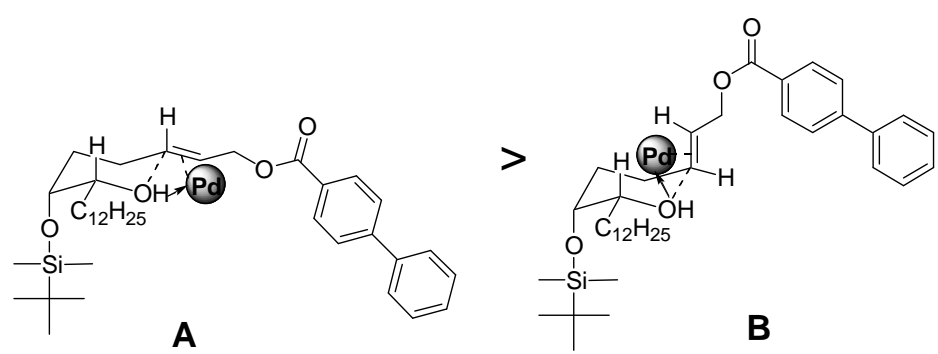

Figure 2.

Determination of the relative stereochemistry of $\mathbf{6 a}$ was performed by 2D-NOESY experiments of 6a', which was afforded by deprotection of the TBS group of $\mathbf{6 a}$ with TBAF. On the other hand, the correlation between the C-2 and C-6 proton of $\mathbf{6 b}$ ' was not observed in 2D-NOESY experiment (Figure 3).
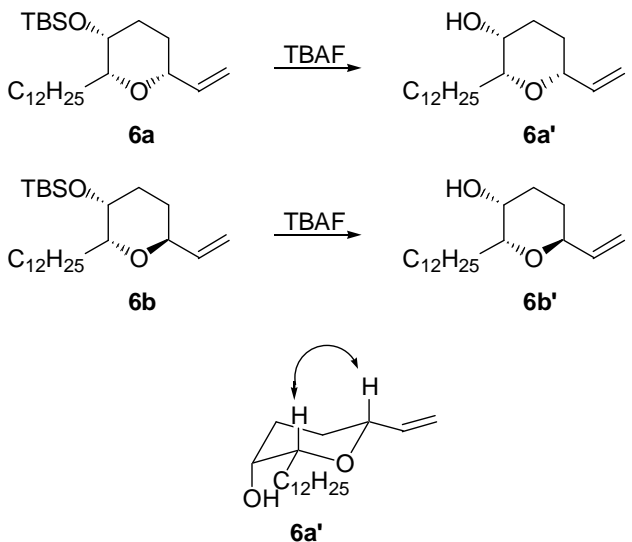

Figure 3. Determination of the relative stereochemistry of $6 \mathbf{a}$ using 2D-NOESY correlations.

Diastereoselective dihydroxylation of $\mathbf{6 a}$ by the Sharpless procedure using (DHQD) ${ }_{2} \mathrm{AQN}$ as a ligand gave $\mathbf{1 4}$ in $84 \%$ de. $^{16}$ The undesired diastereomer was removed by silica gel column chromatography at this stage.

Silylation of the hydroxy group of $\mathbf{1 4}$ with $\mathrm{TBSCl}, \mathrm{Et}_{3} \mathrm{~N}$, and DMAP to give $\mathbf{1 5}$ and subsequence treatment with tetrabutylammonium fluoride furnished terminal epoxide 16. Alkynylation of $\mathbf{1 6}$ with lithium acetylide an ethylenediamine complex to afford $\mathbf{1 7}$ followed by protection of the corresponding hydroxy group with $\mathrm{MOMBr}$ and $i-\operatorname{Pr}_{2} \mathrm{NEt}$ furnished tetrahydropyran moiety 4 (Scheme 3 ).

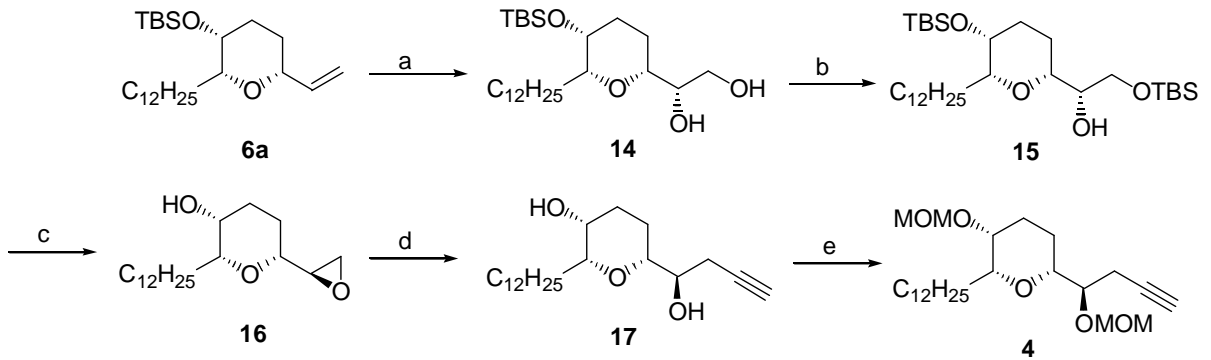

Scheme 3. Synthesis of THP part of 4. Reagents and conditions: (a) (DHQD) ${ }_{2} \mathrm{AQN}, \mathrm{K}_{2} \mathrm{OsO}_{2}(\mathrm{OH})_{4}, \mathrm{~K}_{3} \mathrm{Fe}(\mathrm{CN})_{6}$, $\mathrm{K}_{2} \mathrm{CO}_{3}, \mathrm{MeSO}_{2} \mathrm{NH}_{2}, t-\mathrm{BuOH}-\mathrm{H}_{2} \mathrm{O}$, (95\%, 84\% de); (b) TBSCl, Et ${ }_{3} \mathrm{~N}, \mathrm{DMAP}_{2} \mathrm{CH}_{2} \mathrm{Cl}_{2}$ (98\%); (c) (i) $\mathrm{MsCl}, \mathrm{Et}_{3} \mathrm{~N}$, $\mathrm{CH}_{2} \mathrm{Cl}_{2}$, (ii) TBAF, THF (85\%, 2 steps); (d) lithium acetylide, an ethylenediamine complex (84\%); (e) $\mathrm{MOMBr}$, i-Pr $\mathrm{Pr}_{2} \mathrm{NEt}(77 \%)$.

The $\gamma$-lactone moiety was prepared by Keinan's method ${ }^{17}$ with Jacobsen's hydrolytic kinetic resolution. ${ }^{18,} 19$ Terminal olefin 18 was constructed as we have reported earlier, starting from 1,8-nonadiene. ${ }^{12 b}$ Olefin 18 was 
converted to epoxide 19 using $m$ CPBA. Jacobsen's hydrolytic kinetic resolution of 19 gave $\gamma$-lactone moiety $\mathbf{5}$, with an $R$ configuration at the $\mathrm{C}-8$ position. (Scheme 4$)$.

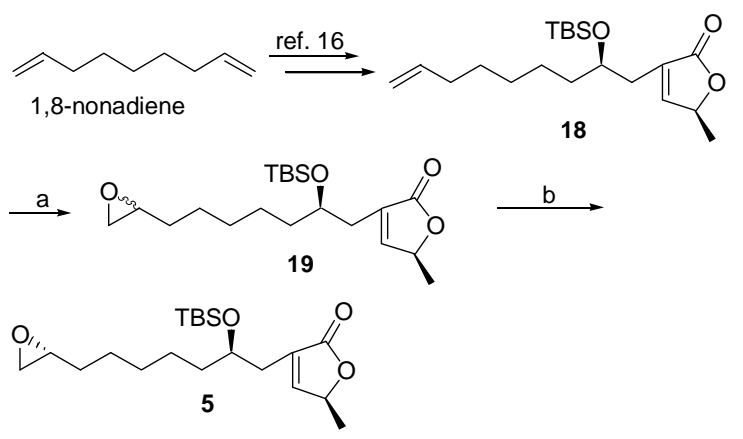

Scheme 4. Synthesis of $\gamma$-lactone part. Reagents and conditions: (a) $m C P B A, \mathrm{CH}_{2} \mathrm{Cl}_{2}(87 \%)$; (b) $(R, R)$-(salen)$\mathrm{Co}^{\text {III }}(\mathrm{OAc}), \mathrm{H}_{2} \mathrm{O}(43 \%)$.

Both segments 4 and 5 were coupled by the reported procedure at $75 \%$ yield, ${ }^{20,21}$ followed by diimide re- duction with $p$ - $\mathrm{TsNHNH}_{2}$ and sodium acetate in ethylene glycol diethyl ether. ${ }^{22}$ Finally, deprotection of the TBS and $\mathrm{MOM}$ ether with $\mathrm{BF}_{3} \bullet \mathrm{Et}_{2} \mathrm{O}$ afforded 1 (Scheme 5).

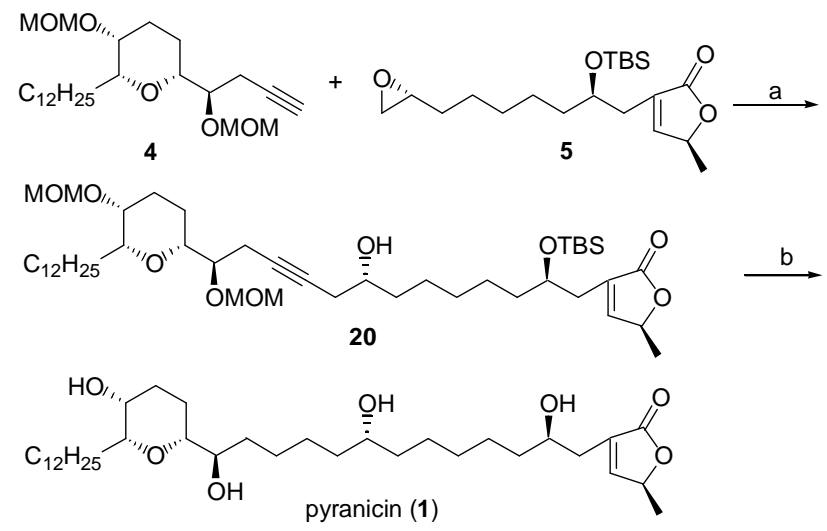

Scheme 5. Completion of the total synthesis of pyranicin. Reagents and conditions: (a) $n-\mathrm{BuLi}_{1} \mathrm{BF}_{3} \cdot \mathrm{Et}_{2} \mathrm{O}(75 \%)$; (b) (i) $p$ - $\mathrm{TsNHNH}_{2}, \mathrm{AcONa}, \mathrm{DME}-\mathrm{H}_{2} \mathrm{O}$ reflux, (ii) $\mathrm{BF}_{3} \cdot \mathrm{Et}_{2} \mathrm{O}$, dimethyl sulfide (98\%, 2 steps).

The spectroscopic data $\left({ }^{1} \mathrm{H}\right.$ NMR, ${ }^{13} \mathrm{C}$ NMR, IR, and MS spectra) of synthetic 1 were in good agreement with those of natural and synthetic pyranicin. ${ }^{5 c, d, 5 f, 6}$ The specific rotation value was consistent with that of synthetic $\mathbf{1}$ which was reported by Takahashi, who reported that natural and synthetic pyranicin were incompatible. ${ }^{5 f}$

Scheme 6 outlines the synthesis of 2. The THP part $\mathbf{6 a}$ was constructed as described in Scheme 3. The $\alpha, \beta-$ unsaturated lactone 21 was prepared following the literature. ${ }^{12 b}$ The segments $\mathbf{6 a}$ and 21 were coupled by the Sonogashira cross-coupling reaction to afford enyne 22 in $51 \%$ yield. ${ }^{23}$ Diimide reduction with $p$-TsNHNH ${ }_{2}$ and sodium acetate in ethylene glycol diethyl ether afforded 23. Finally, deprotection of the TBS and MOM ether with $\mathrm{BF}_{3} \bullet \mathrm{Et}_{2} \mathrm{O}$ afforded 2 (Scheme 6). 

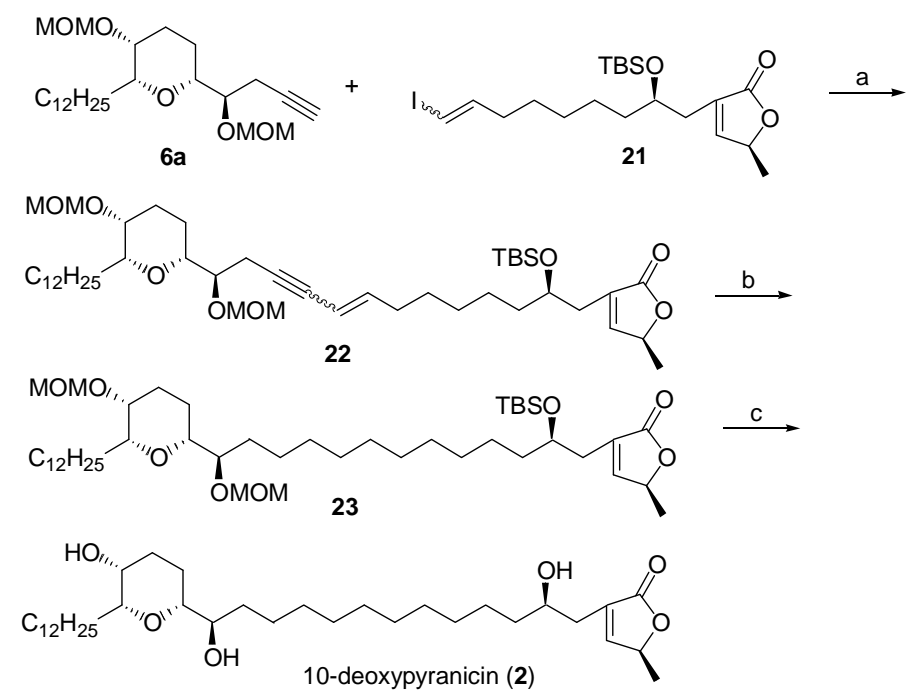

Scheme 6. Synthesis of 10-deoxypyranicin. Reagents and conditions: (a) $10 \mathrm{~mol} \% \mathrm{Cl}_{2} \mathrm{Pd}\left(\mathrm{PPh}_{3}\right)_{2}, \mathrm{CuI}_{2} \mathrm{Et}_{3} \mathrm{~N}$, benzene (51\%); (b) $p-\mathrm{TsNHNH}_{2}, \mathrm{AcONa} \mathrm{DME}-\mathrm{H}_{2} \mathrm{O}$ reflux (68\%); (c) $\mathrm{BF}_{3} \cdot \mathrm{Et}_{2} \mathrm{O}$, dimethyl sulfide (74\%).

Compound 3 was constructed as follows. The THP part 4 was constructed as described in Scheme 3. The lactone 24 was synthesized following the literature procedure from 1,7-heptanediol. ${ }^{24}$ The segments 4 and 24 were coupled by the Sonogashira cross-coupling reaction to afford enyne 25 in $67 \%$ yield. ${ }^{23}$ Diimide reduction with $p$ $\mathrm{TsNHNH}_{2}$ and sodium acetate in ethylene glycol diethyl ether followed by deprotection of the TBS and MOM ether with $\mathrm{BF}_{3} \cdot \mathrm{Et}_{2} \mathrm{O}$ afforded 3 (Scheme 7).

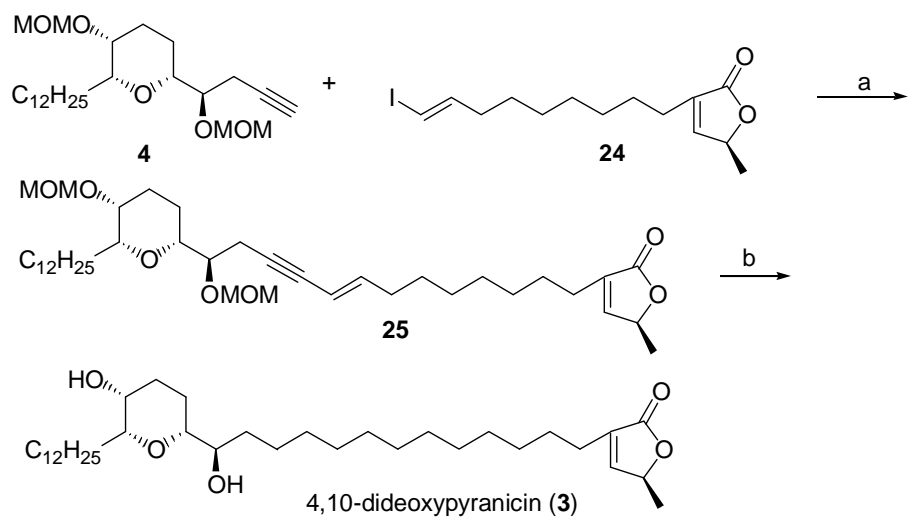

Scheme 7. Synthesis of 4,10-dideoxypyranicin. Reagents and conditions: (a) $10 \mathrm{~mol} \% \mathrm{Cl}_{2} \mathrm{Pd}\left(\mathrm{PPh}_{3}\right)_{2}, \mathrm{CuI}_{2} \mathrm{Et}_{3} \mathrm{~N}$, benzene (67\%); (b) (i) $p$ - $\mathrm{TsNHNH}_{2}, \mathrm{AcONa}, \mathrm{DME}-\mathrm{H}_{2} \mathrm{O}$ reflux , (ii) $\mathrm{BF}_{3} \cdot \mathrm{Et}_{2} \mathrm{O}$, dimethyl sulfide (37\%, 2 steps).

\subsection{Inhibitory action with bovine heart mitochondrial complex I}

Compounds 1, 2, and 3 on bovine heart mitochondrial complex I were tested as inhibitors of bovine heart mitochondrial complex I. ${ }^{\text {la }}$ Bullatacin, one of the most potent natural acetogenins, was used as a control; the $\mathrm{IC}_{50}$ value used, a measure of inhibitory potency, was $0.83 \pm 0.06 \mathrm{nM} .{ }^{1 \mathrm{~b}}$ Under the same conditions, $\mathrm{IC}_{50}$ values of $\mathbf{1}, \mathbf{2}$, and 3 were $7.5 \pm 0.30,3.0 \pm 0.18$, and $31 \pm 0.06 \mathrm{nM}$, respectively. The $\mathrm{IC}_{50}$ values of 1 and 2 were slightly larger than those of annonacin $(3.8 \mathrm{nM})^{1 \mathrm{a}}$ and murisolin $(1.8 \pm 0.10 \mathrm{nM}),{ }^{12 \mathrm{~b}}$ respectively. Under the same experimental conditions, the $\mathrm{IC}_{50}$ values of 3 was significantly larger than that of cis-solamin $(2.2 \pm 0.18 \mathrm{nM}) .^{10 \mathrm{~b}}$ Recently, 
Miyoshi and co-workers found that both the THF and $\gamma$-lactone rings have to occupy simultaneously the two putative binding sites in the enzyme when acetogenins exhibit inhibition. ${ }^{1 \mathrm{c}}$ If the hydroxylated THF ring moiety is replaced to the hydroxylated THP ring, conformation of the alkyl spacer and the hydroxy group in the vicinity of THP ring is drastically changed. Thus, the binding affinity of the toxophore might be weakened compared to THF acetogenins.

\section{Conclusion}

In conclusion, total synthesis of $\mathbf{1}$ and its deoxygenated anologues, $\mathbf{2}$ and $\mathbf{3}$ were achieved from (-)-muricatacin (7) via Pd(II) catalyzed diastereoselective cyclization. Compounds 1, 2, and 3 were investigated in terms of its inhibitory action with bovine heart mitochondrial complex I. The inhibitory activity of these THP-containing acetogenins on complex I was poorer than that of ordinary mono-THF acetogenins.

\section{Experimental}

4.1. General. All melting points were uncorrected. ${ }^{1} \mathrm{H}$ and ${ }^{13} \mathrm{C}$ NMR spectra were measured with a Bruker DRX 500 FT-NMR spectrometer in $\mathrm{CDCl}_{3}$ at 500 and $125 \mathrm{MHz}$, respectively. Chemical shifts were relative to tetramethylsilane as an internal standard. The coupling constants were given in Hz. Mass spectra were obtained on JEOL JMS-HX211A and JMS-HX110A mass spectrometer. IR spectra were recorded with JASCO FT-IR 480 Plus infrared spectrometer. Optical rotations were determined with a JASCO DIP-1000 polarimeter.

4.1.1. (5R,1'R)-5-(1'-Ethoxyethoxytridecyl)tetrahydrofuran-2-one (9). To a solution of (-)-muricatacin (8) (1.49 g, $5.24 \mathrm{mmol})$ in $\mathrm{CH}_{2} \mathrm{Cl}_{2}(30 \mathrm{~mL})$ was added ethyl vinyl ether $(0.60 \mathrm{~mL}, 6.29 \mathrm{mmol})$ and a catalytic amount of PPTS, stirred at room temperature for $15 \mathrm{~h}$. The reaction was quenched with saturated aqueous $\mathrm{NaHCO}_{3}$, and the whole was extracted with AcOEt. The organic layer was washed with brine, dried over $\mathrm{MgSO}_{4}$, filtered, and concentrated. The residue was purified by silica gel column chromatography (hexane/AcOEt $=5: 1$ ) to give 9 (1.86 g, quant.) as a colorless oil. IR (film): $v_{\max }=2925,2854,1780,1464,1377,1176,1127,1094,1056 \mathrm{~cm}^{-1}$; ${ }^{1} \mathrm{H} \mathrm{NMR}\left(\mathrm{CDCl}_{3}, 500 \mathrm{MHz}\right): \delta=4.87(0.5 \mathrm{H}, \mathrm{q}, J=5.2 \mathrm{~Hz}), 4.75(0.5 \mathrm{H}, \mathrm{q}, J=5.2 \mathrm{~Hz}), 4.62(0.5 \mathrm{H}, \mathrm{m}), 4.51$ $(0.5 \mathrm{H}, \mathrm{m}), 3.65-3.45(3 \mathrm{H}, \mathrm{m}), 2.62-2.46(2 \mathrm{H}, \mathrm{m}), 2.25-2.20(1.5 \mathrm{H}, \mathrm{m}), 2.00-1.93(0.5 \mathrm{H}, \mathrm{m}), 1.61-1.52(2 \mathrm{H}, \mathrm{m})$, $1.33(1.5 \mathrm{H}, \mathrm{d}, J=5.0 \mathrm{~Hz}), 1.30(1.5 \mathrm{H}, \mathrm{d}, J=5.0 \mathrm{~Hz}), 1.35-1.22(20 \mathrm{H}, \mathrm{m}), 1.21(1.5 \mathrm{H}, \mathrm{q}, J=7.0 \mathrm{~Hz}), 1.19(1.5 \mathrm{H}$, $\mathrm{t}, J=7.0 \mathrm{~Hz}), 0.88(3 \mathrm{H}, \mathrm{t}, J=7.0 \mathrm{~Hz}) ;{ }^{13} \mathrm{C} \mathrm{NMR}\left(\mathrm{CDCl}_{3}, 125 \mathrm{MHz}\right): \delta=177.6,177.0,100.5,99.2,82.2,80.9$, 78.3, 60.9, 60.3, 31.9, 30.6, 29.9, 29.8 (2C), 29.6 (3C), 29.5 (2C), 29.3, 28.6 (2C), 25.3, 25.2, 24.3, 23.8, 22.7, 20.4, 15.3 (2C), 14.1; HREIMS [(M-Me $)^{+}$]: calcd for $\mathrm{C}_{20} \mathrm{H}_{37} \mathrm{O}_{4}, 341.2692$; found, 341.2681.

\subsection{2. (2E,6R,7R)-Ethyl 7-ethoxyethoxy-6-hydroxy-2-nonadecenoate (10). To a solution of 9 (1.86 g, 5.24} mmol) in $\mathrm{CH}_{2} \mathrm{Cl}_{2}(30 \mathrm{~mL})$ was added DIBALH $(1.03 \mathrm{~mL}, 5.76 \mathrm{mmol})$ at $-78{ }^{\circ} \mathrm{C}$. After being stirred for $15 \mathrm{~min}$ at same temperature, the reaction was quenched with $\mathrm{MeOH}(5.0 \mathrm{~mL})$. The mixture was warmed to room temperature and filtered through celite and silica gel layer, and the filtrate was dried over $\mathrm{MgSO}_{4}$, filtered, and concentrated. This compound was immediately used for the next step without purification. 
Triethylphosphonoacetate $(2.16 \mathrm{~mL}, 10.5 \mathrm{mmol})$ was added to a suspension of $\mathrm{NaH}$ [60\% in mineral oil (503 $\mathrm{mg}$, $12.6 \mathrm{mmol})]$ in THF $(30 \mathrm{~mL})$ at $0{ }^{\circ} \mathrm{C}$ under an argon gas atmosphere and the mixture was stirred for $0.5 \mathrm{~h}$. Crude hemiacetal in THF $(10 \mathrm{~mL})$ was added to a solution. The mixture was stirred for $1.5 \mathrm{~h}$ at $-50{ }^{\circ} \mathrm{C}$. The reaction was quenched with saturated aqueous $\mathrm{NH}_{4} \mathrm{Cl}$, and the whole was extracted with AcOEt. The organic layer was washed with brine, dried over $\mathrm{MgSO}_{4}$, filtered, and concentrated. The residue was purified by silica gel column chromatography (hexane/AcOEt $=10: 1)$ to give $\mathbf{1 0}(1.97 \mathrm{~g}, 88 \%)$ as a colorless oil. IR (film): $v_{\max }=3448,2925$, 2854, 1722, 1655, 1466, 1369, 1267, 1156, 1128, 1096, 1052, $980 \mathrm{~cm}^{-1} ;{ }^{1} \mathrm{H} \mathrm{NMR}\left(\mathrm{CDCl}_{3}, 500 \mathrm{MHz}\right): \delta=6.99$ $(1 \mathrm{H}, \mathrm{m}), 5.85(1 \mathrm{H}, \mathrm{d}, J=16 \mathrm{~Hz}), 4.75(0.4 \mathrm{H}, \mathrm{q}, J=5.5 \mathrm{~Hz}), 4.61(0.6 \mathrm{H}, \mathrm{q}, J=5.5 \mathrm{~Hz}), 4.18(2 \mathrm{H}, \mathrm{m}), 3.70(0.6 \mathrm{H}$, $\mathrm{m}), 3.67-3.63(0.4 \mathrm{H}, \mathrm{m}), 3.59-3.44(2.6 \mathrm{H}, \mathrm{m}), 3.39-3.36(0.4 \mathrm{H}, \mathrm{m}), 3.34-3.30(0.6 \mathrm{H}, \mathrm{m}), 2.51,(0.4 \mathrm{H}, \mathrm{d}, J=5.5$ $\mathrm{Hz}), 2.47-2.41(1 \mathrm{H}, \mathrm{m}), 2.38-2.27(1 \mathrm{H}, \mathrm{m}), 1.65-1.56(2 \mathrm{H}, \mathrm{m}), 1.54-1.47(2 \mathrm{H}, \mathrm{m}), 1.41-1.36(2 \mathrm{H}, \mathrm{m}), 1.35(1.8 \mathrm{H}$, d, $J=5.8 \mathrm{~Hz}), 1.33(1.2 \mathrm{H}, \mathrm{d}, J=6.0 \mathrm{~Hz}), 1.30-1.26(2 \mathrm{H}, \mathrm{m}), 1.22(1.8 \mathrm{H}, \mathrm{t}, J=6.8 \mathrm{~Hz}), 1.21(1.2 \mathrm{H}, \mathrm{t}, J=7.0 \mathrm{~Hz})$, $0.88(3 \mathrm{H}, \mathrm{t}, J=6.8 \mathrm{~Hz}) ;{ }^{13} \mathrm{C} \mathrm{NMR}\left(\mathrm{CDCl}_{3}, 125 \mathrm{MHz}\right): \delta=166.7,166.6,149.0,148.7,121.6,121.5,101.4,100.1$, 83.6, 79.9, 72.3, 71.8, 61.6, 61.1, 60.1 (2C), 32.0, 31.9, 31.6, 31.5, 31.3, 29.9, 29.7, 29.6 (3C), 29.5, 29.3, 28.6, 28.2, 25.3, 25.2, 22.7, 20.4, 20.3, 15.3, 15.2, 14.2, 14.1; HREIMS [(M-OEt) ${ }^{+}$]: calcd for $\mathrm{C}_{23} \mathrm{H}_{43} \mathrm{O}_{4}, 383.3113$; found, 383.3161 .

4.1.3. (2E,6R,7R)-Ethyl 6-(tert-butyldimethylsilyloxy)-7-ethoxyethoxy-2-nonadecenoate (11). To a solution of 10 (1.97 g, $4.61 \mathrm{mmol})$ in $\mathrm{CH}_{2} \mathrm{Cl}_{2}(20 \mathrm{~mL})$ was added imidazole (470 g, $\left.6.92 \mathrm{mmol}\right)$ and TBSCl $(834 \mathrm{mg}, 5.53$ $\mathrm{mmol}$ ). The resulting mixture was stirred at room temperature for $18 \mathrm{~h}$. The reaction was quenched with saturated aqueous $\mathrm{NH}_{4} \mathrm{Cl}$ and the whole was extracted with AcOEt. The organic layer was washed with brine, dried over $\mathrm{MgSO}_{4}$, filtered, and concentrated. The residue was purified by silica gel column chromatography (hexane/AcOEt $=20: 1)$ to give $11(2.32 \mathrm{~g}, 93 \%)$ as a colorless oil. IR (film): $v_{\max }=2926,2855,1724,1655,1464$, 1367, 1257, 1097, 835, $774 \mathrm{~cm}^{-1} ;{ }^{1} \mathrm{H} \mathrm{NMR}\left(\mathrm{CDCl}_{3}, 500 \mathrm{MHz}\right): \delta=7.07-6.95(1 \mathrm{H}, \mathrm{m}), 5.83(1 \mathrm{H}, \mathrm{d}, J=16 \mathrm{~Hz})$, $4.73(0.4 \mathrm{H}, \mathrm{q}, J=5.5 \mathrm{~Hz}), 4.65(0.6 \mathrm{H}, \mathrm{q}, J=5.5 \mathrm{~Hz}), 4.18(2 \mathrm{H}, \mathrm{m}), 3.81-3.78(0.6 \mathrm{H}, \mathrm{m}), 3.70-3.67(0.4 \mathrm{H}, \mathrm{m})$, 3.65-3.42 (2.4H, m), 3.40-3.36 (0.6H, m), 2.41-2.32 (1H, m), 2.17-2.10 (1H, m), 1.79-1.69 (1H, m), 1.65-1.60 $(1 \mathrm{H}, \mathrm{m}), 1.53-1.44(2 \mathrm{H}, \mathrm{m}), 1.30-1.18(29 \mathrm{H}, \mathrm{m}), 0.89(9 \mathrm{H}, \mathrm{s}), 0.88(3 \mathrm{H}, \mathrm{t}, J=7.0 \mathrm{~Hz}), 0.07(3 \mathrm{H}, \mathrm{s}), 0.06(3 \mathrm{H}, \mathrm{s})$; ${ }^{13} \mathrm{C} \mathrm{NMR}\left(\mathrm{CDCl}_{3}, 125 \mathrm{MHz}\right): \delta=166.7,166.6,149.4,149.2,121.3,121.2,101.1,98.9,80.9,78.0,73.0,72.2$, 60.6, 60.1 (2C), 59.8, 31.9, 29.8 (2C), 29.7, 29.6 (3C), 29.3, 29.2, 29.1, 29.0, 28.5, 28.3, 26.5 (2C), 25.8, 22.7, 20.8, 20.2, 18.0, $15.3(2 \mathrm{C}), 14.3,14.1,-4.2(2 \mathrm{C})$; HREIMS [(M-OEt) $\left.{ }^{+}\right]$: calcd for $\mathrm{C}_{29} \mathrm{H}_{57} \mathrm{O}_{4} \mathrm{Si}, 497.4026$; found, 497.3991 .

4.1.4. (2E,6R,7R)-6-(tert-Butyldimethylsilyloxy)-7-ethoxyethoxy-2-nonadecen-1-ol (12). To a solution of 11 (2.32 g, $4.29 \mathrm{mmol})$ in $\mathrm{CH}_{2} \mathrm{Cl}_{2}(20 \mathrm{~mL})$ was added DIBALH $(1.68 \mathrm{~mL}, 9.43 \mathrm{mmol})$ at $-78{ }^{\circ} \mathrm{C}$. After being stirred for $15 \mathrm{~min}$ at the same temperature, the reaction was quenched with $\mathrm{MeOH}(5.0 \mathrm{~mL})$. The mixture was warmed to room temperature, filtered through Celite and silica gel layer. The filtrate was dried over $\mathrm{MgSO}_{4}$, filtered, and concentrated. The residue was purified by silica gel column chromatography (hexane/AcOEt $=10: 1$ ) to give 12 $(2.08 \mathrm{~g}, 97 \%)$ as a colorless oil. IR (film): $v_{\max }=3393,2926,2855,1670,1463,1387,1255,1094,969,836,774$ 
$\mathrm{cm}^{-1} ;{ }^{1} \mathrm{H} \mathrm{NMR}\left(\mathrm{CDCl}_{3}, 500 \mathrm{MHz}\right): \delta=5.74-5.63(2 \mathrm{H}, \mathrm{m}) 4.73(0.4 \mathrm{H}, \mathrm{q}, J=6.3 \mathrm{~Hz}), 4.65(0.6 \mathrm{H}, \mathrm{q}, J=6.3 \mathrm{~Hz})$, 4.09-4.07 (2H, m), 3.81-3.78 (0.6H, m), 3.70-3.66 (0.4H, m), 3.65-3.42 (2.4H, m), 3.38-3.35 (0.6H, m), 2.27-2.17 $(1 \mathrm{H}, \mathrm{m}), 2.01-1.94(1 \mathrm{H}, \mathrm{m}), 1.72-1.61(2 \mathrm{H}, \mathrm{m}), 1.50(1 \mathrm{H}, \mathrm{br}), 1.46-1.38(2 \mathrm{H}, \mathrm{m}), 1.35-1.20(20 \mathrm{H}, \mathrm{m}), 1.30(1.8 \mathrm{H}$, d, $J=6.3 \mathrm{~Hz}), 1.28(1.2 \mathrm{H}, \mathrm{d}, J=6.3 \mathrm{~Hz}), 1.21(1.8 \mathrm{H}, \mathrm{t}, J=7.0 \mathrm{~Hz}), 1.20(1.2 \mathrm{H}, \mathrm{t}, J=7.0 \mathrm{~Hz}), 0.89(9 \mathrm{H}, \mathrm{s}), 0.88$ $(3 \mathrm{H}, \mathrm{t}, J=7.0 \mathrm{~Hz}), 0.07(6 \mathrm{H}, \mathrm{s}) ;{ }^{13} \mathrm{C} \mathrm{NMR}\left(\mathrm{CDCl}_{3}, 125 \mathrm{MHz}\right): \delta=133.5,133.3,129.0,128.9,101.2,98.9,81.1$, 78.3, 73.0, 72.3, 63.8 (2C), 60.6, 60.0, 31.9, 30.3, 30.1, 29.8 (2C), 29.7, 29.6 (4C), 29.3, 29.2, 29.0, 28.6, 28.4, 26.5, 25.8, 22.7, 20.8, 20.3, 18.0, 15.4, 15.3, 14.1, -4.2 (2C); HREIMS [(M-OEE) ${ }^{+}$: calcd for $\mathrm{C}_{25} \mathrm{H}_{51} \mathrm{O}_{2} \mathrm{Si}_{\text {, }}$ 411.3658; found, 411.3657.

4.1.5. (2E,6R,7R)-6-(tert-Butyldimethylsilyloxy)-7-ethoxyethoxy-nonadec-2-ene-3'-phenylbenzoate (13). To a solution of $12(2.08 \mathrm{~g}, 4.16 \mathrm{mmol})$ in pyridine $(20 \mathrm{~mL})$ was added 4-biphenyl-carbonyl chloride (1.35 g, 6.24 mmol) and DMAP $(1.02 \mathrm{~g}, 8.52 \mathrm{mmol})$ at $0^{\circ} \mathrm{C}$. The mixture was stirred at room temperature for $15 \mathrm{~h}$. The reaction was quenched with saturated aqueous $\mathrm{NH}_{4} \mathrm{Cl}$, and the solution was stirred for $3 \mathrm{~h}$. The mixture was extracted with AcOEt. The organic layer was washed with brine, dried over $\mathrm{MgSO}_{4}$, filtered, and concentrated. The residue was purified by silica gel column chromatography (hexane/AcOEt $=20: 1)$ to give $\mathbf{1 3}(2.71 \mathrm{~g}, 96 \%)$ as a colorless oil. IR (film): $v_{\max }=3059,3032,2926,2854,1721,1610,1463,1267,1099,970,835,775,748$, $698 \mathrm{~cm}^{-1} ;{ }^{1} \mathrm{H} \mathrm{NMR}\left(\mathrm{CDCl}_{3}, 500 \mathrm{MHz}\right): \delta=8.12(2 \mathrm{H}, \mathrm{d}, J=8.5 \mathrm{~Hz}), 7.66(2 \mathrm{H}, \mathrm{d}, J=8.5 \mathrm{~Hz}), 7.63(2 \mathrm{H}, \mathrm{d}, J=7.5$ $\mathrm{Hz}), 7.47(2 \mathrm{H}, \mathrm{t}, J=7.5 \mathrm{~Hz}), 7.40(1 \mathrm{H}, \mathrm{t}, J=7.5 \mathrm{~Hz}), 5.92-5.85(1 \mathrm{H}, \mathrm{m}), 5.76-5.70(1 \mathrm{H}, \mathrm{m}), 4.78(2 \mathrm{H}, \mathrm{d}, J=6.0$ $\mathrm{Hz}), 4.73(0.4 \mathrm{H}, \mathrm{q}, J=5.3 \mathrm{~Hz}), 4.66(0.6 \mathrm{H}, \mathrm{q}, J=5.3 \mathrm{~Hz}), 3.82-3.80(0.6 \mathrm{H}, \mathrm{m}), 3.71-3.69(0.4 \mathrm{H}, \mathrm{m}), 3.66-3.42$ $(2.4 \mathrm{H}, \mathrm{m}), 3.39-3.36(0.6 \mathrm{H}, \mathrm{m}), 2.33-2.27(1 \mathrm{H}, \mathrm{m}), 2.07-1.99(1 \mathrm{H}, \mathrm{m}), 1.66-1.64(2 \mathrm{H}, \mathrm{m}), 1.48-1.43(2 \mathrm{H}, \mathrm{m})$, $1.40-1.25(20 \mathrm{H}, \mathrm{m}), 1.31(1.8 \mathrm{H}, \mathrm{d}, J=5.8 \mathrm{~Hz}), 1.29(1.2 \mathrm{H}, \mathrm{d}, J=5.8 \mathrm{~Hz}), 1.20(1.8 \mathrm{H}, \mathrm{t}, J=7.0 \mathrm{~Hz}), 1.18(1.2 \mathrm{H}$, t, $J=7.0 \mathrm{~Hz}), 0.91(\mathrm{~s}, 9 \mathrm{H}), 0.88(3 \mathrm{H}, \mathrm{t}, J=7.0 \mathrm{~Hz}), 0.07(6 \mathrm{H}, \mathrm{s}) ;{ }^{13} \mathrm{C} \mathrm{NMR}\left(\mathrm{CDCl}_{3}, 125 \mathrm{MHz}\right): \delta=166.3,145.6$, $140.1,136.6,136.4,130.1,129.1,128.9,128.1,127.3,127.0,124.0,123.9,101.1,98.9,81.0,78.3,73.1,72.1$, 65.8, 65.7, 60.6, 59.8, 31.9, 30.0, 29.8, 29.7 (2C), 29.6 (3C), 29.4, 29.3, 29.1, 28.5, 28.4, 26.6, 25.9, 22.7, 20.9, 20.3, 18.0, 15.4, 15.3, 14.1, -4.2, -4.5 ; HREIMS $\left[\left(\mathrm{M}-\mathrm{C}_{3} \mathrm{H}_{7} \mathrm{O}\right)^{+}\right]$: calcd for $\mathrm{C}_{39} \mathrm{H}_{61} \mathrm{O}_{4} \mathrm{Si}, 621.4339$; found, 621.4312 .

4.1.6. (2E,6R,7R)-6-(tert-Butyldimethylsilyloxy)-7-hydroxy-2-nonadecenyl-3'-phenylbenzoate (7). To a solution of $13(2.71 \mathrm{~g}, 3.99 \mathrm{mmol})$ in $\mathrm{THF} / \mathrm{H}_{2} \mathrm{O}(1: 1,20 \mathrm{~mL})$ was added a few drops of $0.5 \mathrm{~N} \mathrm{HCl}$. The mixture was stirred at room temperature for $21 \mathrm{~h}$. The reaction was quenched with saturated aqueous $\mathrm{NaHCO}_{3}$, and the whole was extracted with AcOEt. The organic layer was washed with brine, dried over $\mathrm{MgSO}_{4}$, filtered, and concentrated. The residue was purified by silica gel column chromatography (hexane/AcOEt $=15: 1$ ) to give 7 $(2.06 \mathrm{~g}, 85 \%)$ as a colorless oil. $[\alpha]_{\mathrm{D}}^{18}-0.73\left(\mathrm{c} 0.92, \mathrm{CHCl}_{3}\right)$; IR (film): $v_{\max }=3516,3059,3032,2924,2853$, $1719,1609,1463,1267,1100,970,836,776,748,698 \mathrm{~cm}^{-1} ;{ }^{1} \mathrm{H} \mathrm{NMR}\left(\mathrm{CDCl}_{3}, 500 \mathrm{MHz}\right): \delta=7.67-7.65(3 \mathrm{H}, \mathrm{m})$, 7.64-7.61 (3H, m), 7.51-7.46 (2H, m), 7.42-7.38 $(1 \mathrm{H}, \mathrm{m}), 5.89-5.83(1 \mathrm{H}, \mathrm{m}), 5.74-5.69(1 \mathrm{H}, \mathrm{m}), 4.79(2 \mathrm{H}, \mathrm{d}, J=$ $6.0 \mathrm{~Hz}), 3.57-3.54(1 \mathrm{H}, \mathrm{m}), 3.44(1 \mathrm{H}, \mathrm{m}), 2.19-2.06(3 \mathrm{H}, \mathrm{m}), 1.80-1.73(1 \mathrm{H}, \mathrm{m}), 1.59(1 \mathrm{H}, \mathrm{brs}), 1.58-1.51(2 \mathrm{H}$, $\mathrm{m}), 1.46-1.31(3 \mathrm{H}, \mathrm{m}), 1.35-1.20(17 \mathrm{H}, \mathrm{m}), 0.91(9 \mathrm{H}, \mathrm{s}), 0.88(3 \mathrm{H}, \mathrm{t}, J=7.0 \mathrm{~Hz}), 0.10(3 \mathrm{H}, \mathrm{s}), 0.09(3 \mathrm{H}, \mathrm{s}) ;{ }^{13} \mathrm{C}$ 
NMR $\left(\mathrm{CDCl}_{3}, 125 \mathrm{MHz}\right): \delta=166.1,145.5,139.9,135.8,130.1,129.0,128.8,128.0,127.2,126.9,124.5,124.2$, 81.6, 74.4, 72.6, 65.4, 33.8, 32.7, 31.8, 29.6 (2C), 29.6 (5C), 29.3, 27.9, 25.9, 25.8, 22.6, 18.0, 14.1, -4.2, -4.6; HRFABMS [(M- $\left.\left.\mathrm{H}_{2} \mathrm{O}+\mathrm{H}\right)^{+}\right]$: calcd for $\mathrm{C}_{38} \mathrm{H}_{59} \mathrm{O}_{3} \mathrm{Si}$, 591.4233; found, 591.4212 .

\subsection{7. (2R,3R,6R)-3-(tert-Butyldimethylsilyloxy)-2-dodecyl-6-(1'-ethenyl)tetrahydropyran (6a). To a solution} of 7 (2.06 g, $3.39 \mathrm{mmol})$ in dry $\mathrm{CH}_{2} \mathrm{Cl}_{2}(15 \mathrm{~mL})$ was added $\left(\mathrm{CH}_{3} \mathrm{CN}\right)_{2} \mathrm{PdCl}_{2}(86.9 \mathrm{mg}, 0.339 \mathrm{mmol})$ at $-10{ }^{\circ} \mathrm{C}$ under an argon gas atmosphere, and the mixture was stirred at the same temperature for $4 \mathrm{~h}$. The reaction was quenched with saturated aqueous $\mathrm{NH}_{4} \mathrm{Cl}$ and the whole was extracted with AcOEt. The organic layer was washed with brine, dried over $\mathrm{MgSO}_{4}$, filtered, and concentrated. The residue was purified by PTLC (hexane/AcOEt = $50: 1)$ to give the mixture of $\mathbf{6 a}$ and $\mathbf{6 b}(1.03 \mathrm{~g}, 74 \%)$ as a colorless oil. Further purification by PTLC (hexane/AcOEt $=50: 1)$ to give 6a $(953 \mathrm{mg}, 69 \%) ;[\alpha]^{20}{ }_{\mathrm{D}}+8.97\left(c 1.00, \mathrm{CHCl}_{3}\right) ; \mathrm{IR}(\mathrm{film}): v_{\max }=3080,3014$, 2925, 2854, 1648, 1464, 1253, 1087, 918, 835, $772 \mathrm{~cm}^{-1} ;{ }^{1} \mathrm{H}$ NMR $\left(\mathrm{CDCl}_{3}, 500 \mathrm{MHz}\right): \delta=5.91(1 \mathrm{H}, \mathrm{ddd}, J=$ $17.3,10.5,6.0 \mathrm{~Hz}), 5.22(1 \mathrm{H}, \mathrm{dt}, J=17.3,1.2 \mathrm{~Hz}), 5.08(1 \mathrm{H}, \mathrm{dt}, J=10.5,1.1 \mathrm{~Hz}), 3.81(1 \mathrm{H}, \mathrm{dd}, J=10.5,6.0 \mathrm{~Hz})$, $3.61(1 \mathrm{H}, \mathrm{m}), 3.26(1 \mathrm{H}, \mathrm{t}, J=6.6 \mathrm{~Hz}), 1.88-1.85(1 \mathrm{H}, \mathrm{m}), 1.68-1.60(4 \mathrm{H}, \mathrm{m}), 1.41-1.30(4 \mathrm{H}, \mathrm{m}), 1.35-1.20(17 \mathrm{H}$, m), $0.91(9 \mathrm{H}, \mathrm{s}), 0.88(3 \mathrm{H}, \mathrm{t}, J=6.8 \mathrm{~Hz}), 0.06(3 \mathrm{H}, \mathrm{s}), 0.05(3 \mathrm{H}, \mathrm{s}) ;{ }^{13} \mathrm{C} \mathrm{NMR}\left(\mathrm{CDCl}_{3}, 125 \mathrm{MHz}\right): \delta=139.7$, 114.7, 80.1, 78.5, 66.4, 32.3, 31.9, 31.7, 29.8, 29.7, 29.6 (2C), 29.4, 25.9, 25.8, 25.7 (2C), 22.7, 18.2, 14.1, -4.5, -4.7; HRCIMS [(M+H) ${ }^{+}$: calcd for $\mathrm{C}_{25} \mathrm{H}_{51} \mathrm{O}_{2} \mathrm{Si}, 411.3658$; found: 411.3661 .

\subsection{8. (2R,3R,6R,1'S)-3-(tert-Butyldimethylsilyloxy)-6-(1',2'-dihydroxyethyl)-2-dodecyltetrahydropyran}

(14). A suspension of AQN(DHQD) $2(18.0 \mathrm{mg}, 20.9 \mu \mathrm{mol}), \mathrm{K}_{2} \mathrm{OsO}_{2}(\mathrm{OH})_{4}(3.1 \mathrm{mg}, 8.4 \mu \mathrm{mol}), \mathrm{K}_{3}\left[\mathrm{Fe}(\mathrm{CN})_{6}\right](2.06$ $\mathrm{g}, 6.27 \mathrm{mmol})$ and $\mathrm{K}_{2} \mathrm{CO}_{3}(867 \mathrm{mg}, 6.27 \mathrm{mmol})$ in $t-\mathrm{BuOH} / \mathrm{H}_{2} \mathrm{O}(1: 1,10 \mathrm{~mL})$ was stirred at $0{ }^{\circ} \mathrm{C}$ for $15 \mathrm{~min}$. A solution of $6 \mathbf{a}(856 \mathrm{mg}, 2.09 \mathrm{mmol})$ in $t-\mathrm{BuOH}(3.0 \mathrm{~mL})$ and $\mathrm{CH}_{3} \mathrm{SO}_{2} \mathrm{NH}_{2}(199 \mathrm{mg}, 2.09 \mathrm{mmol})$ were added to the suspension. The mixture was stirred $22 \mathrm{~h}$ at same temperature. The reaction was quenched with saturated aqueous $\mathrm{Na}_{2} \mathrm{SO}_{3}$, and the whole was extracted with AcOEt. The organic layer was washed with brine, dried over $\mathrm{MgSO}_{4}$, filtered, and concentrated. The crude product showed $84 \%$ de by ${ }^{1} \mathrm{H}$ NMR analysis of the corresponding Mosher ester. The residue was purified by PTLC (hexane/AcOEt = 3:1) to give $14(834 \mathrm{mg}, 90 \%)$ as a colorless oil. $[\alpha]_{\mathrm{D}}^{21}+3.09$ (c 1.40, $\mathrm{CHCl}_{3}$ ); IR (film): $v_{\max }=3389,2925,2854,1464,1376,1253,1097,1027,836,772$ $\mathrm{cm}^{-1} ;{ }^{1} \mathrm{H} \mathrm{NMR}\left(\mathrm{CDCl}_{3}, 500 \mathrm{MHz}\right): \delta=3.88(1 \mathrm{H}, \mathrm{d}, J=11.5 \mathrm{~Hz}), 3.70(1 \mathrm{H}, \mathrm{m}), 3.61(1 \mathrm{H}, \mathrm{m}), 3.60(1 \mathrm{H}, \mathrm{m}), 3.55$ $(1 \mathrm{H}, \mathrm{m}), 3.22(1 \mathrm{H}, \mathrm{dd}, J=5.0,4.5 \mathrm{~Hz}), 2.80(1 \mathrm{H}, \mathrm{d}, J=8.0 \mathrm{~Hz}), 2.62(1 \mathrm{H}, \mathrm{d}, J=7.5 \mathrm{~Hz}), 1.89(1 \mathrm{H}, \mathrm{m}), 1.81(1 \mathrm{H}$, $\mathrm{m}), 1.66-1.60(2 \mathrm{H}, \mathrm{m}), 1.66-1.54(4 \mathrm{H}, \mathrm{m}), 1.41-1.36(2 \mathrm{H}, \mathrm{m}), 1.35-1.20(16 \mathrm{H}, \mathrm{m}), 0.91(9 \mathrm{H}, \mathrm{s}), 0.88(3 \mathrm{H}, \mathrm{t}, J=$ $6.8 \mathrm{~Hz}), 0.06(3 \mathrm{H}, \mathrm{s}), 0.04(3 \mathrm{H}, \mathrm{s}) ;{ }^{13} \mathrm{C} \mathrm{NMR}\left(\mathrm{CDCl}_{3}, 125 \mathrm{MHz}\right): \delta=80.4,80.3,73.0,66.5,63.7,32.2,31.9,31.2$ (2C), 29.7, 29.6 (2C), 29.3, 25.8 (2C), 25.6, 22.7, 21.5, 18.1, 14.1, -4.5, -4.9; HREIMS [(M-tBu ${ }^{+}$]: calcd for $\mathrm{C}_{21} \mathrm{H}_{43} \mathrm{O}_{4} \mathrm{Si}, 387.2931$; found, 387.2924 .

\subsection{8. (2R,3R,6R,1'S)-3-(tert-Butyldimethylsilyloxy)-6-(2'-tert-butyldimethylsilyloxy-1'-hydroxyethyl)-2-} dodecyltetrahydrofuran (15). To a solution of $14(834 \mathrm{mg}, 1.88 \mathrm{mmol}), \mathrm{Et}_{3} \mathrm{~N}(0.39 \mathrm{~mL}, 2.82 \mathrm{mmol})$, and DMAP (2.3 mg, $0.019 \mathrm{mmol})$ in $\mathrm{CH}_{2} \mathrm{Cl}_{2}(10 \mathrm{~mL})$ was added $\mathrm{TBSCl}(312 \mathrm{mg}, 2.07 \mathrm{mmol})$. The mixture was 
stirred at room temperature for $4 \mathrm{~h}$. The reaction was quenched with saturated aqueous $\mathrm{NH}_{4} \mathrm{Cl}$ and the whole was extracted with AcOEt. The organic layer was washed with brine, dried over $\mathrm{MgSO}_{4}$, filtered, and concentrated. The residue was purified by PTLC (hexane/AcOEt $=20: 1)$ to give $15(1.02 \mathrm{~g}, 98 \%)$ as a colorless oil. $[\alpha]^{21}{ }_{\mathrm{D}}$ -3.57 (c 1.03, $\mathrm{CHCl}_{3}$ ); IR (film): $v_{\max }=3478,2926,2855,1463,1254,1098,836,774 \mathrm{~cm}^{-1} ;{ }^{1} \mathrm{H} \mathrm{NMR}\left(\mathrm{CDCl}_{3}\right.$, $500 \mathrm{MHz}): \delta=3.74(2 \mathrm{H}, \mathrm{d}, J=4.5 \mathrm{~Hz}), 3.58(1 \mathrm{H}, \mathrm{m}), 3.54-3.53(1 \mathrm{H}, \mathrm{m}), 3.24-3.30(1 \mathrm{H}, \mathrm{m}), 3.20(1 \mathrm{H}, \mathrm{dd}, J=$ 7.8, $3.8 \mathrm{~Hz}), 2.50(1 \mathrm{H}, \mathrm{d}, J=5.5 \mathrm{~Hz}), 1.90-1.87(1 \mathrm{H}, \mathrm{m}), 1.76-1.69(1 \mathrm{H}, \mathrm{m}), 1.55-1.62(5 \mathrm{H}, \mathrm{m}), 1.36-1.34(2 \mathrm{H}$, $\mathrm{m}), 1.40-1.25(17 \mathrm{H}, \mathrm{m}), 0.90(18 \mathrm{H}, \mathrm{s}), 0.88(3 \mathrm{H}, \mathrm{t}, J=7.0 \mathrm{~Hz}), 0.07(6 \mathrm{H}, \mathrm{s}), 0.05(3 \mathrm{H}, \mathrm{s}), 0.04(3 \mathrm{H}, \mathrm{s}) ;{ }^{13} \mathrm{C}$ NMR $\left(\mathrm{CDCl}_{3}, 125 \mathrm{MHz}\right): \delta=80.1,77.3,73.7,67.0,63.4,32.3,31.9,31.5,29.7$ (2C), $29.6(2 \mathrm{C}), 29.4,25.9,25.8(4 \mathrm{C})$, 22.7, 21.7, 18.3, 18.2, 14.1, -4.5, -4.7, -5.4, -5.5; HREIMS [(M-Me $\left.)^{+}\right]$: calcd for $\mathrm{C}_{30} \mathrm{H}_{63} \mathrm{O}_{4} \mathrm{Si}_{2}, 543.4265$; found, 543.4263 .

4.1.9. (2R,3R,6R,1'R)-2-Dodecyl-6-(1',2'-epoxyethyl)tetrahydropyran-3-ol (16). To a solution of 15 (1.02 g, $1.84 \mathrm{mmol})$ and $\mathrm{Et}_{3} \mathrm{~N}(0.51 \mathrm{ml}, 3.68 \mathrm{mmol})$ in $\mathrm{CH}_{2} \mathrm{Cl}_{2}(10 \mathrm{~mL})$ was added $\mathrm{MsCl}(0.17 \mathrm{~mL}, 2.21 \mathrm{mmol})$ at $0{ }^{\circ} \mathrm{C}$. The mixture was stirred at room temperature for $4 \mathrm{~h}$. The reaction was quenched with saturated aqueous $\mathrm{NH}_{4} \mathrm{Cl}$, and whole was extracted with AcOEt. The organic layer was washed with brine, dried over $\mathrm{MgSO}_{4}$, filtered, and concentrated. The residue was dissolved in THF $(5.0 \mathrm{~mL})$, and then TBAF [1.0 M solution in THF (7.2 mL, 7.2 mmol)] was added to this solution at $0^{\circ} \mathrm{C}$. After the mixture was stirred for $12 \mathrm{~h}$, the reaction was quenched with saturated aqueous $\mathrm{NH}_{4} \mathrm{Cl}$ and the whole was extracted with AcOEt. The organic layer was washed with brine, dried over $\mathrm{MgSO}_{4}$, filtered, and concentrated. The residue was purified by PTLC (hexane/AcOEt = 20:1) to give 16 (488 mg, 85\%) as a colorless oil. $[\alpha]^{22}+12.4$ (c 1.06, $\mathrm{CHCl}_{3}$ ); IR (film): $v_{\max }=3451,3046,2924,2853,1466$, $1084 \mathrm{~cm}^{-1} ;{ }^{1} \mathrm{H} \mathrm{NMR}\left(\mathrm{CDCl}_{3}, 500 \mathrm{MHz}\right): \delta=3.61(1 \mathrm{H}, \mathrm{m}), 3.33(1 \mathrm{H}, \mathrm{t}, J=7.0 \mathrm{~Hz}), 3.28(1 \mathrm{H}, \mathrm{ddd}, J=11.5,4.5$, $2.5 \mathrm{~Hz}), 3.01(1 \mathrm{H}, \mathrm{dd}, J=7.3,4.8 \mathrm{~Hz}), 2.78(1 \mathrm{H}, \mathrm{m}), 2.69(1 \mathrm{H}, \mathrm{dd}, J=5.0,3.0 \mathrm{~Hz}), 2.03(2 \mathrm{H}, \mathrm{m}), 1.78(2 \mathrm{H}, \mathrm{m})$, 1.70-1.60 (2H, m), 1.53-1.40 (2H, m), 1.40-1.20 (19H, m), $0.88(3 \mathrm{H}, \mathrm{t}, J=7.5 \mathrm{~Hz},) ;{ }^{13} \mathrm{C} \mathrm{NMR}\left(\mathrm{CDCl}_{3}, 125\right.$ MHz): $\delta=80.1,78.0,65.8,54.0,43.8,31.9,31.6,30.5,29.6$ (2C), 29.5 (2C), 29.3, 25.5, 22.7, 21.9, 14.1; HRFABMS $\left[(\mathrm{M}+\mathrm{H})^{+}\right]$: calcd for $\mathrm{C}_{19} \mathrm{H}_{37} \mathrm{O}_{3}, 313.2743$; found, 313.2741 .

4.1.10. (2R,3R,6R,1'R)-2-Dodecyl-6-(1'-hydroxy-3'-butyn-1'-yl)tetrahydropyran-3-ol (17). To a suspension of lithium acetylide, an ethylenediamine complex (1.44 g, $15.6 \mathrm{mmol})$ in DMSO (15 mL) was added 16 (488 mg, $1.56 \mathrm{mmol})$ in DMSO $(5.0 \mathrm{~mL})$ at $0{ }^{\circ} \mathrm{C}$. The reaction mixture was stirred for $18 \mathrm{~h}$ at room temperature. The reaction was quenched with saturated aqueous $\mathrm{NH}_{4} \mathrm{Cl}$ and the whole was extracted with AcOEt. The organic layer was washed with brine, dried over $\mathrm{MgSO}_{4}$, filtered, and concentrated. The residue was purified by PTLC (hexane/AcOEt $=20: 1)$ to give $17(442 \mathrm{mg}, 84 \%)$ as a colorless oil. $[\alpha]^{21}{ }_{\mathrm{D}}-16.1\left(c 1.00, \mathrm{CHCl}_{3}\right)$; IR (film): $v_{\max }$ $=3380,3313,2924,2853,2119,1465,1089 \mathrm{~cm}^{-1} ;{ }^{1} \mathrm{H} \mathrm{NMR}\left(\mathrm{CDCl}_{3}, 500 \mathrm{MHz}\right): \delta=3.62(2 \mathrm{H}, \mathrm{m}), 3.47(1 \mathrm{H}, \mathrm{m})$, $3.38(1 \mathrm{H}, \mathrm{m}), 2.68(1 \mathrm{H}, \mathrm{brs}), 2.52(1 \mathrm{H}, \mathrm{ddd}, J=17.0,6.0,2.5 \mathrm{~Hz}), 2.43(1 \mathrm{H}, \mathrm{ddd}, J=17.0,6.0,2.5 \mathrm{~Hz}), 2.17(1 \mathrm{H}$, brs.), $2.02(1 \mathrm{H}, \mathrm{t}, J=2.5 \mathrm{~Hz}), 2.04(1 \mathrm{H}, \mathrm{m}), 1.77-1.70(2 \mathrm{H}, \mathrm{m}), 1.68-1.62(2 \mathrm{H}, \mathrm{m}), 1.52-1.46(2 \mathrm{H}, \mathrm{m}), 1.40-1.20$ $(20 \mathrm{H}, \mathrm{m}), 0.88(3 \mathrm{H}, \mathrm{t}, J=7.0 \mathrm{~Hz}) ;{ }^{13} \mathrm{C} \mathrm{NMR}\left(\mathrm{CDCl}_{3}, 125 \mathrm{MHz}\right): \delta=80.5,80.2,79.2,72.2,70.2,66.1,31.9,31.6$, 30.5, 29.7, 29.6 (3C), 29.3, 25.6, 23.8, 23.0, 22.7, 21.5, 14.1; HRFABMS [(M+Na) $\left.{ }^{+}\right]$: calcd for $\mathrm{C}_{21} \mathrm{H}_{38} \mathrm{O}_{3} \mathrm{Na}$, 
361.2719; found, 361.2720.

4.1.11.

(2R,3R,6R,1'R)-2-Dodecyl-3-methoxymethoxy-6-(1'-methoxymethoxy-3'-butyn-1'-

yl)tetrahydropyran (4). To a solution of $17(442 \mathrm{mg}, 1.31 \mathrm{mmol})$ in dry $\mathrm{CH}_{2} \mathrm{Cl}_{2}(5.0 \mathrm{~mL})$ was added $i-\mathrm{Pr}_{2} \mathrm{NEt}$ $(0.69 \mathrm{~mL}, 3.93 \mathrm{mmol})$ and $\mathrm{MOMBr}(0.26 \mathrm{~mL}, 3.14 \mathrm{mmol})$ at $0{ }^{\circ} \mathrm{C}$. The mixture was stirred at room temperature for $16 \mathrm{~h}$. The reaction was quenched with saturated aqueous $\mathrm{NH}_{4} \mathrm{Cl}$ and the whole was extracted with AcOEt. The organic layer was washed with brine, dried over $\mathrm{MgSO}_{4}$, filtered, and concentrated. The residue was purified by PTLC (hexane/AcOEt $=5: 1)$ to give $4(430 \mathrm{mg}, 77 \%)$ as a colorless oil. $[\alpha]^{19}{ }_{\mathrm{D}}-32.5$ (c 1.08, $\left.\mathrm{CHCl}_{3}\right)$; IR (film) $v_{\max }=3312,2925,2853,2120,1467,1151,1103,1038,918 \mathrm{~cm}^{-1} ;{ }^{1} \mathrm{H} \mathrm{NMR}\left(\mathrm{CDCl}_{3}, 500 \mathrm{MHz}\right): \delta=4.77(1 \mathrm{H}, \mathrm{d}$, $J=7.0 \mathrm{~Hz}), 4.76(1 \mathrm{H}, \mathrm{d}, J=7.0 \mathrm{~Hz}), 4.75(1 \mathrm{H}, \mathrm{d}, J=7.0 \mathrm{~Hz}), 4.61(1 \mathrm{H}, \mathrm{d}, J=7.0 \mathrm{~Hz}), 3.69(1 \mathrm{H}, \mathrm{m}), 3.62(1 \mathrm{H}$, ddd, $J=11.5,5.0,1.5 \mathrm{~Hz}), 3.53(1 \mathrm{H}, \mathrm{m}), 3.40(3 \mathrm{H}, \mathrm{s}), 3.39(3 \mathrm{H}, \mathrm{s}), 3.34(1 \mathrm{H}, \mathrm{m}), 2.66(1 \mathrm{H}, \mathrm{ddd}, J=17.0,6.3$, $2.5 \mathrm{~Hz}), 2.43(1 \mathrm{H}$, ddd, $J=17.0,5.0,2.5 \mathrm{~Hz}), 2.13(1 \mathrm{H}, \mathrm{m}), 1.96(1 \mathrm{H}, \mathrm{t}, J=2.5 \mathrm{~Hz}), 1.83-1.73(2 \mathrm{H}, \mathrm{m}), 1.62-1.59$ $(1 \mathrm{H}, \mathrm{m}), 1.48-1.39(3 \mathrm{H}, \mathrm{m}), 1.40-1.25(19 \mathrm{H}, \mathrm{m}), 0.88(3 \mathrm{H}, \mathrm{t}, J=7.0 \mathrm{~Hz}) ;{ }^{13} \mathrm{C} \mathrm{NMR}\left(\mathrm{CDCl}_{3}, 125 \mathrm{MHz}\right): \delta=96.7$, 95.2, 81.1, 80.2, 78.9, 77.5, 71.2, 69.6, 55.7 (2C), 31.9, 31.8, 29.6 (3C), 29.3, 27.8, 25.6, 22.8, 21.8, 21.0, 14.1; HRFABMS [(M+Na) $\left.{ }^{+}\right]$: calcd for $\mathrm{C}_{25} \mathrm{H}_{47} \mathrm{O}_{5}, 427.3423$; found, 427.3424 .

4.1.12. (5S,2'R,8'RS)-3-(2'-tert-Butyldimethylsilyloxy-8'-epoxynonan-1'-yl)-5-methyl-3,4-dihydrofuran-2one (19). To a solution of $18(98.8 \mathrm{mg}, 0.281 \mathrm{mmol})$ in $\mathrm{CH}_{2} \mathrm{Cl}_{2}(2.0 \mathrm{~mL})$ was added $\mathrm{mCPBA}(149 \mathrm{mg}, 0.562$ mmol) and $\mathrm{NaHCO}_{3}(155 \mathrm{mg}, 1.85 \mathrm{mmol})$ at $0{ }^{\circ} \mathrm{C}$. The reaction mixture was stirred at same temperature for $17 \mathrm{~h}$. The reaction was quenched with saturated aqueous $\mathrm{Na}_{2} \mathrm{~S}_{2} \mathrm{O}_{3}$ and $\mathrm{NaHCO}_{3}$ and the whole was extracted with AcOEt. The organic layer was washed with brine, dried over $\mathrm{MgSO}_{4}$, filtered, and concentrated. The residue was purified by PTLC (hexane/AcOEt $=7: 1)$ to give $19(89.9 \mathrm{mg}, 87 \%)$ as a colorless oil. IR (film) $v_{\max }=3046,2931$, 2857, 1756, 1075, 836, $775 \mathrm{~cm}^{-1} ;{ }^{1} \mathrm{H} \mathrm{NMR}\left(\mathrm{CDCl}_{3}, 500 \mathrm{MHz}\right): \delta=7.11(1 \mathrm{H}, \mathrm{d}, J=1.0 \mathrm{~Hz}), 5.01(1 \mathrm{H}, \mathrm{qd}, J=7.0$, $1.0 \mathrm{~Hz}), 3.98-3.94(1 \mathrm{H}, \mathrm{m}), 2.91-2.88(1 \mathrm{H}, \mathrm{m}), 2.74(1 \mathrm{H}, \mathrm{dd}, J=4.8,4.3 \mathrm{~Hz}), 2.46(1 \mathrm{H}, \mathrm{dd}, J=5.0,2.5 \mathrm{~Hz}), 2.43$ $(3 \mathrm{H}, \mathrm{dd}, J=4.3,1.3 \mathrm{~Hz}), 1.58-1.50(2 \mathrm{H}, \mathrm{m}), 1.49-1.44(5 \mathrm{H}, \mathrm{m}), 1.41(3 \mathrm{H}, \mathrm{d}, J=7.0 \mathrm{~Hz}), 1.35(2 \mathrm{H}, \mathrm{m}), 0.88(9 \mathrm{H}$, s), $0.05(3 \mathrm{H}, \mathrm{s}), 0.03(3 \mathrm{H}, \mathrm{s}) ;{ }^{13} \mathrm{C} \mathrm{NMR}\left(\mathrm{CDCl}_{3}, 125 \mathrm{MHz}\right): \delta=174.0,151.5,130.8,77.4,70.1,52.3,47.0,36.8$, $32.7,32.4,29.5,25.9,25.1,25.0,19.0,18.0,-4.5$.

\subsubsection{3. (5S,2'R,8'R)-3-(2'-tert-Butyldimethylsilyloxy-8'-epoxynonan-1'-yl)-5-methyl-3,4-dihydrofuran-2-} one (5). To a solution of $19(89.9 \mathrm{mg}, 0.244 \mathrm{mmol})$ and $\mathrm{AcOH}(0.28 \mu \mathrm{L}, 4.88 \mu \mathrm{mol})$ in THF $(20 \mu \mathrm{L})$ was added $(R, R)$-(salen)- $\mathrm{Co}^{\mathrm{III}}(0.7 \mathrm{mg}, 1.22 \mu \mathrm{mol})$ and $\mathrm{H}_{2} \mathrm{O}(2.0 \mu \mathrm{L})$ at $0{ }^{\circ} \mathrm{C}$. The mixture was stirred at room temperature for $24 \mathrm{~h}$. The mixture was concentrated and purified by PTLC (hexane/AcOEt $=5: 1)$ to give $5(38.6 \mathrm{mg}, 43 \%)$ as a colorless oil. $[\alpha]^{20}{ }_{\mathrm{D}}+22.2\left(\mathrm{c} 1.02, \mathrm{CHCl}_{3}\right.$ ); IR (film) $v_{\max }=3045,2930,2856,1755,1076,836,775 \mathrm{~cm}^{-1} ;{ }^{1} \mathrm{H}$ NMR $\left(\mathrm{CDCl}_{3}, 500 \mathrm{MHz}\right): \delta=7.12(1 \mathrm{H}, \mathrm{d}, J=1.0 \mathrm{~Hz}), 5.01(1 \mathrm{H}, \mathrm{qd}, J=6.8,1.0 \mathrm{~Hz}), 3.98-3.94(1 \mathrm{H}, \mathrm{m}), 2.91$ $(1 \mathrm{H}, \mathrm{m}), 2.74(1 \mathrm{H}, \mathrm{dd}, J=4.8,4.3 \mathrm{~Hz}), 2.46(1 \mathrm{H}, \mathrm{dd}, J=5.0,2.8 \mathrm{~Hz}), 2.43(3 \mathrm{H}, \mathrm{dd}, J=4.3,1.3 \mathrm{~Hz}), 1.54-1.50$ $(2 \mathrm{H}, \mathrm{m}), 1.46-1.43(5 \mathrm{H}, \mathrm{m}), 1.41(3 \mathrm{H}, \mathrm{d}, J=7.0 \mathrm{~Hz}), 1.35-1.34(2 \mathrm{H}, \mathrm{m}), 0.88(9 \mathrm{H}, \mathrm{s}), 0.05(3 \mathrm{H}, \mathrm{s}), 0.03(3 \mathrm{H}, \mathrm{s})$;

${ }^{13} \mathrm{C} \mathrm{NMR}\left(\mathrm{CDCl}_{3}, 125 \mathrm{MHz}\right): \delta=174.0,151.5,130.9,77.4,70.2,52.3,47.1,36.8,32.8,32.4,29.5,25.9$ (3C), 
25.1, 19.0, 18.1, -4.4 (2C); HRFABMS [(M+H) ${ }^{+}$: calcd for $\mathrm{C}_{20} \mathrm{H}_{37} \mathrm{O}_{4} \mathrm{Si}, 369.2461$; found, 369.2455.

\subsubsection{4. (2R,3R,6R,1'R,6'R,12' $R, 5$ ' $S)-6$-(12'-tert-Butyldimethylsilyloxy-6'-hydroxy-1'-methoxymethoxy-13'-} [5"-methyl-3",4”-dihydrofuran-2"-on-3”-yl]-tridec-3'-ynyl)-2-dodecyl-3-methoxymethoxytetrahydropyran

(20). To a solution of $6 \mathbf{a}(224 \mathrm{mg}, 0.525 \mathrm{mmol})$ in dry THF $(5.0 \mathrm{~mL})$ was added $n$-BuLi [1.56 M solution in hexane $(0.30 \mathrm{~mL}, 0.473 \mathrm{mmol})]$ at $-78{ }^{\circ} \mathrm{C}$ under an argon gas atmosphere. After being stirred for $1 \mathrm{~h}$ at the same temperature, $\mathrm{BF}_{3} \cdot \mathrm{Et}_{2} \mathrm{O}(0.13 \mathrm{~mL}, 0.420 \mathrm{mmol})$ was added and the mixture was stirred for $30 \mathrm{~min}$ at $-78^{\circ} \mathrm{C}$. To the resultant mixture was added $5(38.6 \mathrm{mg}, 0.105 \mathrm{mmol})$ in dry THF $(1.0 \mathrm{~mL})$ and stirred for $2 \mathrm{~h}$ at $-78{ }^{\circ} \mathrm{C}$. The reaction was quenched with saturated aqueous $\mathrm{NH}_{4} \mathrm{Cl}$ and extracted with EtOAc. The organic layer was washed with brine and dried over $\mathrm{MgSO}_{4}$, filtered, and concentrated. The residue was purified by PTLC (hexane/EtOAc = 3:1) to give $20(62.8 \mathrm{mg}, 75 \%)$ as a colorless oil. $[\alpha]_{D}^{21}-15\left(c 0.72, \mathrm{CHCl}_{3}\right)$; IR (film) $v_{\max }=3477,2926,2854$, 2120, 1757, 1463, 1150, 1099, 1033, 836, $775 \mathrm{~cm}^{-1} ;{ }^{1} \mathrm{H}$ NMR $\left(\mathrm{CDCl}_{3}, 500 \mathrm{MHz}\right): \delta=7.12(1 \mathrm{H}, \mathrm{s}), 5.00(1 \mathrm{H}, \mathrm{q}, J$ $=6.8 \mathrm{~Hz}), 4.83-4.74(3 \mathrm{H}, \mathrm{m}), 4.61(1 \mathrm{H}, \mathrm{d}, J=7.0 \mathrm{~Hz}), 3.97-3.93(1 \mathrm{H}, \mathrm{m}), 3.68-3.66(2 \mathrm{H}, \mathrm{m}), 3.57-3.52(2 \mathrm{H}, \mathrm{m})$, $3.39(3 \mathrm{H}, \mathrm{s}), 3.38(3 \mathrm{H}, \mathrm{s}), 3.32(1 \mathrm{H}, \mathrm{m}), 2.63-2.59(1 \mathrm{H}, \mathrm{m}), 2.43-2.34(5 \mathrm{H}, \mathrm{m}), 2.25(1 \mathrm{H}, \mathrm{dd}, J=16.5,7.0 \mathrm{~Hz})$, 2.14-2.12 (1H, m), 1.74-1.82 (2H, m), 1.59-1.52 (1H, m), 1.49-1.45 (10H, m), $1.41(3 \mathrm{H}, \mathrm{d}, J=6.8 \mathrm{~Hz}), 1.40-1.26$ $(22 \mathrm{H}, \mathrm{m}), 0.88(3 \mathrm{H}, \mathrm{t}, J=6.8 \mathrm{~Hz}), 0.87(9 \mathrm{H}, \mathrm{s}), 0.05(3 \mathrm{H}, \mathrm{s}), 0.03(3 \mathrm{H}, \mathrm{s}) ;{ }^{13} \mathrm{C} \mathrm{NMR}\left(\mathrm{CDCl}_{3}, 125 \mathrm{MHz}\right): \delta=$ 174.0, 151.5, 130.8, 96.6, 95.2, 80.3, 79.7, 79.4, 78.1, 77.8, 77.4, 71.1, 70.2, 70.1 (2C), 55.7, 55.6, 36.9, 36.3, 32.7, 31.9, 31.8, 29.7 (3C), 29.6, 29.3, 27.9 (2C), 27.8, 25.9, 25.1 (3C), 22.7, 21.8, 21.3, 19.0, 18.0, 14.1, -4.5; HRFABMS [(M+Na) $\left.{ }^{+}\right]$: calcd for $\mathrm{C}_{45} \mathrm{H}_{82} \mathrm{O}_{9} \mathrm{SiNa}, 817.5626$; found, 817.5630.

4.1.15. Pyranicin (1). To a solution of $20(62.8 \mathrm{mg}, 0.0789 \mathrm{mmol})$ in 1,2-diethoxyethane $(1.0 \mathrm{~mL})$ was added $p$ $\mathrm{TsHNNH}_{2}(1.03 \mathrm{~g}, 5.52 \mathrm{mmol})$, and the resulting mixture was stirred for $0.5 \mathrm{~h}$ at $120{ }^{\circ} \mathrm{C}$. A solution of AcONa (550 mg, $6.71 \mathrm{mmol})$ in $\mathrm{H}_{2} \mathrm{O}(1.0 \mathrm{~mL})$ was added dropwise to a solution and stirred at same temperature for $4 \mathrm{~h}$. The reaction was quenched with $\mathrm{H}_{2} \mathrm{O}$, and the whole was extracted with AcOEt. The organic layer was washed with brine, dried over $\mathrm{MgSO}_{4}$, filtered, and concentrated. The residue was dissolved in dimethyl sulfide $(1.0 \mathrm{~mL})$ and a few drops of $\mathrm{BF}_{3} \cdot \mathrm{Et}_{2} \mathrm{O}$ was added at $0{ }^{\circ} \mathrm{C}$. After being stirred for $1 \mathrm{~h}$, the reaction was quenched with saturated aqueous $\mathrm{NaHCO}_{3}$ and the whole was extracted with AcOEt. The organic layer was washed with brine, dried over $\mathrm{MgSO}_{4}$, filtered, and concentrated. The residue was purified by PTLC (hexane/AcOEt $=1: 5$ ) to give pyranicin (1) $(41 \mathrm{mg}, 87 \%)$ as a colorless wax. $[\alpha]^{19}{ }_{\mathrm{D}}+17\left(\mathrm{c} 0.41, \mathrm{CHCl}_{3}\right)$; IR (film) $v_{\max }=3392,2925,2853$, 1741, $1085 \mathrm{~cm}^{-1} ;{ }^{1} \mathrm{H}$ NMR $\left(\mathrm{CDCl}_{3}, 500 \mathrm{MHz}\right): \delta=7.19(1 \mathrm{H}, \mathrm{d}, J=1.0 \mathrm{~Hz}), 5.07(1 \mathrm{H}, \mathrm{qd}, J=6.7,1.0 \mathrm{~Hz}), 3.85$ $(1 \mathrm{H}, \mathrm{m}), 3.61(3 \mathrm{H}, \mathrm{m}), 3.46(1 \mathrm{H}, \mathrm{m}), 3.34(1 \mathrm{H}, \mathrm{dd}, J=7.5,6.0 \mathrm{~Hz}), 3.19(1 \mathrm{H}, \mathrm{ddd}, J=11.0,7.0,2.0 \mathrm{~Hz}), 2.76$ (1H, brs.), 2.52 (1H, dt, $J=15.2,1.6 \mathrm{~Hz}), 2.45$ (1H, brs.), 2.40 (1H, dd, $J=15.3,8.3 \mathrm{~Hz}), 2.02-1.99(2 \mathrm{H}, \mathrm{m}), 1.70$ (1H, brs.), 1.70-1.50 (3H, m), 1.48-1.46 (6H, m), $1.43(3 \mathrm{H}, \mathrm{d}, J=6.5 \mathrm{~Hz}), 1.42-1.26(33 \mathrm{H}, \mathrm{m}), 0.88(3 \mathrm{H}, \mathrm{t}, J=$ $6.8 \mathrm{~Hz}) ;{ }^{13} \mathrm{C} \mathrm{NMR}\left(\mathrm{CDCl}_{3}, 125 \mathrm{MHz}\right): \delta=174.6,151.9,131.1,81.2,80.0,78.0,74.0,71.8,69.9,66.1,37.3,33.4$, 32.3, 31.9, 31.6, 30.5, 29.7, 29.6 (4C), 29.5, 29.3, 25.6 (2C), 25.5, 25.4, 25.3, 22.7, 21.6, 19.1, 14.1; HRFABMS $\left[(\mathrm{M}+\mathrm{H})^{+}\right]$: calcd for $\mathrm{C}_{35} \mathrm{H}_{65} \mathrm{O}_{7}, 597.4730$; found, 597.4745 . 
4.1.16. (5'EZ,2R,3R,6R,1'R,12'R,5’S)-6-(12'-tert-Butyldimethylsilyloxy-1'-methoxymethoxy-13'-[5”methyl-3",4”-dihydrofuran-2"-on-3"-yl]tridec-5'-en-3'-ynyl)-3-methoxymethoxytetrahydropyran (22). To a solution of $21(70 \mathrm{mg}, 0.146 \mathrm{mmol})$ in benzene $(1.0 \mathrm{~mL})$ were added $\mathrm{Et}_{3} \mathrm{~N}(0.05 \mathrm{~mL}, 0.29 \mathrm{mmol})$ and $\mathrm{Cl}_{2} \mathrm{Pd}\left(\mathrm{PPh}_{3}\right)_{2}(10.3 \mathrm{mg}, 14.5 \mu \mathrm{mol})$. After the mixture had been stirred for $30 \mathrm{~min}$, the solution of $6 \mathbf{a}(62 \mathrm{mg}$, $0.146 \mathrm{mmol})$ and $\mathrm{CuI}(5.5 \mathrm{mg}, 0.029 \mathrm{mmol})$ were added and the resulting mixture was stirred for $19 \mathrm{~h}$. The reaction was quenched with saturated aqueous $\mathrm{NH}_{4} \mathrm{Cl}(5 \mathrm{~mL})$ and the whole was extracted with ether. The organic layer was washed with brine, dried over $\mathrm{MgSO}_{4}$, filtered, and concentrated. The residue was purified by PTLC (hexane/AcOEt $=1: 5)$ to give $22\left(57 \mathrm{mg}, 51 \%\right.$ ) as a colorless oil. IR (film) $v_{\max }=2926,2854,2214,1758,1464$, 1150, 1036, 919, 836, $775 \mathrm{~cm}^{-1} ;{ }^{1} \mathrm{H}$ NMR $\left(\mathrm{CDCl}_{3}, 500 \mathrm{MHz}\right): \delta=7.13(1 \mathrm{H}, \mathrm{d}, J=1.0 \mathrm{~Hz}), 6.03(0.9 \mathrm{H}, \mathrm{dt}, J=$ 15.8, $7.1 \mathrm{~Hz}), 5.82(0.2 \mathrm{H}, \mathrm{m}), 5.43(0.9 \mathrm{H}, \mathrm{d}, J=15.8 \mathrm{~Hz}), 5.01(1 \mathrm{H}, \mathrm{qd}, J=6.3,1.0 \mathrm{~Hz}), 4.77(1 \mathrm{H}, \mathrm{d}, J=6.5 \mathrm{~Hz})$, $4.76(2 \mathrm{H}, \mathrm{s}), 4.61(1 \mathrm{H}, \mathrm{d}, J=7.0 \mathrm{~Hz}), 3.95(1 \mathrm{H}, \mathrm{m}), 3.68(1 \mathrm{H}, \mathrm{m}), 3.59(1 \mathrm{H}, \mathrm{ddd}, J=11.5,4.9,1.6 \mathrm{~Hz}), 3.53(1 \mathrm{H}$, m), $3.40(3 \mathrm{H}, \mathrm{s}), 3.39(3 \mathrm{H}, \mathrm{s}), 3.35(1 \mathrm{H}, \mathrm{m}), 2.80-2.75(1 \mathrm{H}, \mathrm{m}), 2.60-2.50(1 \mathrm{H}, \mathrm{m}), 2.42(2 \mathrm{H}, \mathrm{m}), 2.12(1 \mathrm{H}, \mathrm{m})$, $2.07(2 \mathrm{H}, \mathrm{m}), 1.83-1.72(2 \mathrm{H}, \mathrm{m}), 1.69(1 \mathrm{H}, \mathrm{m}), 1.62-1.54(1 \mathrm{H}, \mathrm{m}), 1.48-1.25(34 \mathrm{H}, \mathrm{m}), 1.41(3 \mathrm{H}, \mathrm{d}, J=6.3 \mathrm{~Hz})$,

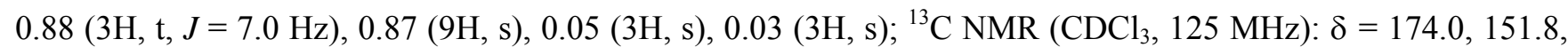
151.5, 143.6, 142.8, 130.8, 109.8, 109.3, 95.5, 95.0, 84.9, 80.4, 80.3, 80.2, 77.7, 77.5, 71.1, 70.1, 69.8, 55.7, 36.8, 32.9, 32.7, 31.9, 31.7, 29.7, 29.6 (2C), 29.3, 29.2, 28.7, 27.6, 25.8 (2C), 25.6, 24.9, 22.7, 21.9, 21.8, 19.0, 18.0, 14.0, -4.5 (2C); HRFABMS [(M+H) ${ }^{+}$: calcd for $\mathrm{C}_{45} \mathrm{H}_{79} \mathrm{O}_{8} \mathrm{Si}$, 775.5544; found, 775.5533.

\subsubsection{7. $\quad\left(2 R, 3 R, 6 R, 1^{\prime} R, 12 ' R, 5\right.$ 'S)-6-(12'-tert-Butyldimethylsilyloxy-1'-methoxymethoxy-13'-[5”'-methyl-} 3",4"-dihydrofuran-2"-on-3"-yl]tridecyl-2-dodecyl-3-methoxymethoxytetrahydropyran (23). To a solution of 22 (38 mg, $0.049 \mathrm{mmol})$ in 1,2-diethoxyethane $(1.0 \mathrm{~mL})$ was added $p-\mathrm{TsHNNH}_{2}(672 \mathrm{mg}, 3.43 \mathrm{mmol})$, and the resulting mixture was stirred for $0.5 \mathrm{~h}$ at $120^{\circ} \mathrm{C}$. A solution of $\mathrm{AcONa}(341 \mathrm{mg}, 4.16 \mathrm{mmol})$ in $\mathrm{H}_{2} \mathrm{O}(1.0 \mathrm{~mL}) \mathrm{was}$ added dropwise to a solutionan and stirred at same temperature for $4 \mathrm{~h}$. The reaction was quenched with $\mathrm{H}_{2} \mathrm{O}$, and the whole was extracted with AcOEt. The organic layer was washed with brine, dried over $\mathrm{MgSO}_{4}$, filtered, and concentrated. The residue was purified by PTLC (hexane/AcOEt $=1: 3)$ to give $23(26 \mathrm{mg}, 68 \%)$ as a colorless oil. $[\alpha]^{19}{ }_{\mathrm{D}}+9.1\left(c 0.26, \mathrm{CHCl}_{3}\right)$; IR (film) $v_{\max }=2925,2854,1760,1465,1373,1318,1254,1210,1150,1100,1035$, 919, 837, $775 \mathrm{~cm}^{-1} ;{ }^{1} \mathrm{H} \mathrm{NMR}\left(\mathrm{CDCl}_{3}, 500 \mathrm{MHz}\right): \delta=7.13(1 \mathrm{H}, \mathrm{d}, J=1.0 \mathrm{~Hz}), 5.01(1 \mathrm{H}, \mathrm{qd}, J=6.6,1.0 \mathrm{~Hz})$, $4.81(1 \mathrm{H}, \mathrm{d}, J=6.5 \mathrm{~Hz}), 4.77(1 \mathrm{H}, J=7.0 \mathrm{~Hz}), 4.70(1 \mathrm{H}, J=6.5 \mathrm{~Hz}), 4.62(1 \mathrm{H}, J=7.0 \mathrm{~Hz}), 3.94(1 \mathrm{H}, \mathrm{m}), 3.52$ $(2 \mathrm{H}, \mathrm{m}), 3.38(1 \mathrm{H}, \mathrm{m}), 3.38(6 \mathrm{H}, \mathrm{s}), 3.32(1 \mathrm{H}, \mathrm{m}), 2.42(2 \mathrm{H}, \mathrm{dd}, J=8.0,5.5 \mathrm{~Hz}), 2.12(1 \mathrm{H}, \mathrm{m}), 1.76-1.51(6 \mathrm{H}, \mathrm{m})$, 1.47-1.25 (43H, m), $1.41(3 \mathrm{H}, \mathrm{d}, J=6.6 \mathrm{~Hz}), 0.88(3 \mathrm{H}, \mathrm{t}, J=6.8 \mathrm{~Hz}), 0.87(9 \mathrm{H}, \mathrm{s}), 0.05(3 \mathrm{H}, \mathrm{s}), 0.02(3 \mathrm{H}, \mathrm{s}) ;{ }^{13} \mathrm{C}$ NMR $\left(\mathrm{CDCl}_{3}, 125 \mathrm{MHz}\right): \delta=174.0,151.5,130.8,97.0,95.1,80.7,80.0,79.8,77.5,71.1,70.2,55.7,37.0,32.7$, $31.9,31.8,30.6,29.8,29.7$ (2C), 29.6 (3C), 29.3, 27.8, 25.9, 25.8, 25.7, 25.2, 25.1, 22.7, 22.0, 19.0, 18.0, 14.1, -4.5 (2C); HRFABMS [(M+H) ${ }^{+}$]: calcd for $\mathrm{C}_{45} \mathrm{H}_{85} \mathrm{O}_{8} \mathrm{Si}$, 781.6014; found, 781.6019.

4.1.18. 10-Deoxypyranicin (2). To a solution of compound $23(24 \mathrm{mg}, 0.031 \mathrm{mmol})$ in dimethyl sulfide $(1.0 \mathrm{~mL})$ was added a few drops of $\mathrm{BF}_{3} \cdot \mathrm{Et}_{2} \mathrm{O}$ at $0{ }^{\circ} \mathrm{C}$. After being stirred for $1 \mathrm{~h}$, the reaction was quenched with saturated aqueous $\mathrm{NaHCO}_{3}$ and the whole was extracted with AcOEt. The organic layer was washed with brine, dried over 
$\mathrm{MgSO}_{4}$, filtered, and concentrated. The residue was purified by PTLC (hexane/AcOEt = 1:2) to give $2(13 \mathrm{mg}$, $74 \%$ ) as a colorless solid. M.P. $36-37{ }^{\circ} \mathrm{C} ;[\alpha]^{19}{ }_{\mathrm{D}}+12\left(\mathrm{c} 0.20, \mathrm{CHCl}_{3}\right)$; IR (film) $v_{\max }=3413,2924,2853,1741$, 1465, 1085, 1028, 849, $721 \mathrm{~cm}^{-1} ;{ }^{1} \mathrm{H}$ NMR $\left(\mathrm{CDCl}_{3}, 500 \mathrm{MHz}\right): \delta=7.19(1 \mathrm{H}, \mathrm{d}, J=1.0 \mathrm{~Hz}), 5.07(1 \mathrm{H}, \mathrm{qd}, J=6.8$, $1.0 \mathrm{~Hz}), 3.85(1 \mathrm{H}, \mathrm{m}), 3.61(1 \mathrm{H}, \mathrm{m}), 3.45(1 \mathrm{H}, \mathrm{m}), 3.34(1 \mathrm{H}, \mathrm{dd}, J=7.8,5.8 \mathrm{~Hz}), 3.20(1 \mathrm{H}, \mathrm{ddd}, J=11.3,7.0,2.3$ Hz), $2.53(1 \mathrm{H}, \mathrm{dt}, J=15.3,1.6 \mathrm{~Hz}), 2.40(1 \mathrm{H}, \mathrm{dd}, J=15.3,8.3 \mathrm{~Hz}), 2.00(2 \mathrm{H}, \mathrm{m}), 1.71-1.25(44 \mathrm{H}, \mathrm{m}), 1.43(3 \mathrm{H}$, $\mathrm{d}, J=6.8 \mathrm{~Hz}), 0.88(3 \mathrm{H}, \mathrm{t}, J=7.0 \mathrm{~Hz}) ;{ }^{13} \mathrm{C} \mathrm{NMR}\left(\mathrm{CDCl}_{3}, 125 \mathrm{MHz}\right): \delta=174.6,151.8,131.2,81.2,80.0,78.0$, 74.0, 70.0, 66.2, 37.4, 33.3, 32.4, 31.9, 31.6, 30.6, 29.7, 29.6 (4C), 29.5, 29.3, 25.6 (2C), 25.3, 22.7, 21.6, 19.1, 14.1; HRFABMS $\left[(\mathrm{M}+\mathrm{H})^{+}\right]$: calcd for $\mathrm{C}_{35} \mathrm{H}_{65} \mathrm{O}_{6}, 581.4781$; found, 581.4787.

\subsubsection{9. (5'E,2R,3R,6R,1'R,5”S)-2-Dodecyl-3-methoxymethoxy-6-(1'-methoxymethoxy-13'-[5"-methyl-3”,4”-} dihydrofuran-2"-on-3"-yl]tridec-5'-en-3'-ynyl)tetrahydropyran (25). To a solution of 24 (30 mg, 0.086 $\mathrm{mmol})$ in benzene $(1.0 \mathrm{~mL})$ were added $\mathrm{Et}_{3} \mathrm{~N}(0.024 \mathrm{~mL}, 0.17 \mathrm{mmol})$ and $\mathrm{Cl}_{2} \mathrm{Pd}\left(\mathrm{PPh}_{3}\right)_{2}(6.1 \mathrm{mg}, 8.6 \mu \mathrm{mol})$. After the mixture had been stirred for $30 \mathrm{~min}$, the solution of $4(37 \mathrm{mg}, 0.087 \mathrm{mmol})$ and $\mathrm{CuI}(3.3 \mathrm{mg}, 0.017 \mathrm{mmol})$ were added and the resulting mixture was stirred for $19 \mathrm{~h}$. The reaction was quenched with saturated aqueous $\mathrm{NH}_{4} \mathrm{Cl}(5 \mathrm{~mL})$ and the whole was extracted with ether. The organic layer was washed with brine, dried over $\mathrm{MgSO}_{4}$, filtered, and concentrated. The residue was purified by PTLC (hexane/AcOEt = 1:5) to give 25 (37 mg, $67 \%$ ) as a colorless oil. IR (film) $v_{\max }=2925,2853,2219,1758,1465,1372,1318,1212,1150,1102,1035,955$, 918, $722 \mathrm{~cm}^{-1} ;{ }^{1} \mathrm{H} \mathrm{NMR}\left(\mathrm{CDCl}_{3}, 500 \mathrm{MHz}\right): \delta=6.99(1 \mathrm{H}, \mathrm{d}, J=1.5 \mathrm{~Hz}), 6.04(1 \mathrm{H}, \mathrm{dt}, J=15.5,7.3 \mathrm{~Hz}), 5.43$ $(1 \mathrm{H}, \mathrm{d}, J=15.5 \mathrm{~Hz}), 5.00(1 \mathrm{H}, \mathrm{qd}, J=6.8,1.5 \mathrm{~Hz}), 4.77(1 \mathrm{H}, \mathrm{d}, J=6.5 \mathrm{~Hz}), 4.76(2 \mathrm{H}, \mathrm{s}), 4.61(1 \mathrm{H}, \mathrm{d}, J=6.5$ Hz), $3.68(1 \mathrm{H}, \mathrm{m}), 3.59(1 \mathrm{H}, \mathrm{ddd}, J=11.5,4.9,1.6 \mathrm{~Hz}), 3.53(1 \mathrm{H}, \mathrm{m}), 3.40(3 \mathrm{H}, \mathrm{s}), 3.39(3 \mathrm{H}, \mathrm{s}), 3.34(1 \mathrm{H}, \mathrm{m})$, $2.74(1 \mathrm{H}, \mathrm{ddd}, J=17.0,6.3,1.8 \mathrm{~Hz}), 2.53(1 \mathrm{H}, \mathrm{ddd}, J=17.0,5.4,1.6 \mathrm{~Hz}), 2.26(2 \mathrm{H}, \mathrm{t}, J=7.0 \mathrm{~Hz}), 2.13(1 \mathrm{H}, \mathrm{m})$, $2.07(2 \mathrm{H}, \mathrm{m}), 1.83-1.72(2 \mathrm{H}, \mathrm{m}), 1.62-1.60(2 \mathrm{H}, \mathrm{m}), 1.57-1.51(2 \mathrm{H}, \mathrm{m}), 1.50-1.25(34 \mathrm{H}, \mathrm{m}), 1.41(3 \mathrm{H}, \mathrm{d}, J=6.8$ $\mathrm{Hz}), 0.88(3 \mathrm{H}, \mathrm{t}, J=6.8 \mathrm{~Hz}) ;{ }^{13} \mathrm{C} \mathrm{NMR}\left(\mathrm{CDCl}_{3}, 125 \mathrm{MHz}\right): \delta=173.9,148.9,143.6,134.3,109.8,96.6,95.1$, 84.9, 80.4, 80.2, 79.2, 77.8, 77.4, 71.1, 55.7, 32.9, 31.9, 31.8, 29.7, 29.6 (2C), 29.4, 29.3, 29.1, 29.0, 28.7, 27.8, 27.4, 25.6, 25.2, 22.7, 21.9, 21.8, 19.2, 14.1; HRFABMS $\left[(\mathrm{M}+\mathrm{H})^{+}\right]$: calcd for $\mathrm{C}_{39} \mathrm{H}_{67} \mathrm{O}_{7}, 647.4886$; found, 647.4890 .

4.1.20. 4,10-Dideoxypyranicin (3). To a solution of $25(25.0 \mathrm{mg}, 0.039 \mathrm{mmol})$ in 1,2-diethoxyethane $(1.0 \mathrm{~mL})$ was added $p-\mathrm{TsHNNH}_{2}(531 \mathrm{mg}, 2.71 \mathrm{mmol})$, and the resulting mixture was stirred for $0.5 \mathrm{~h}$ at $120{ }^{\circ} \mathrm{C}$. A solution of $\mathrm{AcONa}(270 \mathrm{mg}, 3.29 \mathrm{mmol})$ in $\mathrm{H}_{2} \mathrm{O}(1.0 \mathrm{~mL})$ was added dropwise to a solutionan and stirred at same temperature for $4 \mathrm{~h}$. The reaction was quenched with $\mathrm{H}_{2} \mathrm{O}$, and the whole was extracted with AcOEt. The organic layer was washed with brine, dried over $\mathrm{MgSO}_{4}$, filtered, and concentrated. The residue was dissolved in dimethyl sulfide $(1.0 \mathrm{~mL})$ and a few drops of $\mathrm{BF}_{3} \cdot \mathrm{Et}_{2} \mathrm{O}$ was added at $0{ }^{\circ} \mathrm{C}$. After being stirred for $1 \mathrm{~h}$, the reaction was quenched with saturated aqueous $\mathrm{NaHCO}_{3}$ and the whole was extracted with AcOEt. The organic layer was washed with brine, dried over $\mathrm{MgSO}_{4}$, filtered, and concentrated. The residue was purified by PTLC (hexane/AcOEt $=1: 5)$ to give $3\left(8 \mathrm{mg}, 37 \%, 2\right.$ steps) as a colorless wax. M.p. $61-63^{\circ} \mathrm{C} ;[\alpha]^{18}{ }_{\mathrm{D}}+12.5(c) 0.40$, $\mathrm{CHCl}_{3}$ ) ; IR (film) $v_{\max }=3398,2919,2850,1754,1467,1375,1319,1200,1086,1028,874,721 \mathrm{~cm}^{1} ;{ }^{1} \mathrm{H}$ NMR 
$\left(\mathrm{CDCl}_{3}, 500 \mathrm{MHz}\right): \delta=6.99(1 \mathrm{H}, \mathrm{d}, J=1.5 \mathrm{~Hz}), 5.00(1 \mathrm{H}, \mathrm{qd}, J=6.8,1.5 \mathrm{~Hz}), 3.61(1 \mathrm{H}, \mathrm{m}), 3.45(1 \mathrm{H}, \mathrm{m}), 3.34$ $(1 \mathrm{H}, \mathrm{dd}, J=7.8,5.8 \mathrm{~Hz}), 3.19(1 \mathrm{H}, \mathrm{ddd}, J=11.0,7.8,2.5 \mathrm{~Hz}), 2.66(1 \mathrm{H}, \mathrm{brs}),. 2.26(2 \mathrm{H}, \mathrm{dt}, J=7.8 \mathrm{~Hz}), 2.00(1 \mathrm{H}$, m), $1.82(1 \mathrm{H}, \mathrm{d}, J=8.0 \mathrm{~Hz}), 1.70-1.25(47 \mathrm{H}, \mathrm{m}), 1.41(3 \mathrm{H}, \mathrm{d}, J=6.8 \mathrm{~Hz}), 0.88(3 \mathrm{H}, \mathrm{t}, J=6.8 \mathrm{~Hz}) ;{ }^{13} \mathrm{C} \mathrm{NMR}$ $\left(\mathrm{CDCl}_{3}, 125 \mathrm{MHz}\right): \delta=173.9,148.9,134.3,81.3,80.0,77.4,74.1,66.2,32.4,31.9,31.6,30.6,29.7$ (2C), 29.6 (2C), 29.5, 29.4, 29.3, 29.2, 27.4, 25.6, 25.3, 25.2, 22.7, 21.6, 19.2, 14.1; HRFABMS [(M+H $\left.)^{+}\right]$: calcd for $\mathrm{C}_{35} \mathrm{H}_{65} \mathrm{O}_{5}, 565.4832$; found, 565.4820.

\subsection{Biochemical methods}

Bovine heart submitochondrial particles were prepared by the method of Matsuno-Yagi and Hatefi, ${ }^{26}$ and stored in a buffer containing $0.25 \mathrm{M}$ sucrose and $10 \mathrm{mM}$ Tris- $\mathrm{HCl}(\mathrm{pH} 7.4)$ at $-82{ }^{\circ} \mathrm{C}$. The NADH oxidase activity in the particles was followed spectrometrically with a Shimadzu UV-3000 $\left(340 \mathrm{~nm}, \varepsilon=6.2 \mathrm{mM}^{-1} \mathrm{~cm}^{-1}\right)$ at $30{ }^{\circ} \mathrm{C}$. The reaction medium $\left(2.5 \mathrm{~mL}\right.$ ) contained $0.25 \mathrm{M}$ sucrose, $1 \mathrm{mM} \mathrm{MgCl}_{2}$, and $50 \mathrm{mM}$ phosphate buffer (pH 7.4). The final mitochondrial protein concentration was $30 \mu \mathrm{g}$ of protein $/ \mathrm{mL}$. The reaction was started by adding $50 \mu \mathrm{M}$ $\mathrm{NADH}$ after the equilibration of particles with inhibitor for $5 \mathrm{~min}$. The $\mathrm{IC}_{50}$ values were averaged from three independent experiments.

\section{Acknowledgements}

This work was supported in part by a Grant-in-aid from the Japan Society for the Promotion of Science (90313840).

\section{References and notes}

1. (a) Miyoshi, H.; Ohshima, M.; Shimada, H.; Akagi, T.; Iwamura, H.; McLaughlin, J. L. Biochim. Biophys. Acta 1998, 1365, 443-452. (b) Abe, M.; Murai, M.; Ichimaru, N.; Kenmochi, A.; Yoshida, T.; Kubo, A.; Kimura, Y.; Moroda, A.; Makabe, H.; Nishioka, T.; Miyoshi, H. Biochemistry 2005, 44, 14898-14906. (c) Abe, M.; Kubo, A.; Yamamoto, S.; Murai, M.; Hattori, Y.; Makabe, H.; Nishioka, T.; Miyoshi, H. Biochemistry 2008, 47, 6260-6266.

2. Bermejo, A.; Figadère, B.; Zafra-Polo, M.-C.; Barrachina, I.; Estornell, E.; Cortes, B. L. Nat. Prod. Rep. 2005, 22, 269-303.

3. Alali, F. Q.; Liu, X.-X.; McLaughlin, J. L. J. Nat. Prod. 1999, 62, 504-540.

4. Zafra-Polo, M. C.; Figadère, B.; Gallardo, T.; Tormo, J. R.; Cortes, D. Phytochemistry, 1998, 48, 1087-1117.

5. For recent synthesis of THP containing annonaceous acetogenins: (a) Crimmins, M. T.; Zhang, Y.; Diaz, F. A.

Org. Lett. 2006, 8, 2369-2372; (b) Bandur, N. G.; Brückner, D.; Hoffmann, R. W.; Koert, U. Org. Lett. 2006, 8, 
3829-3831; (c) Strand, D.; Rein, T. Org. Lett. 2005, 7, 199-202; (d) Strand, D.; Norrby, P.-O.; Rein, T. J. Org. Chem. 2006, 71, 1879-1891. (e) Crisóstomo, F. R. P.; Carrillo, R.; León, L. G. Martin, T.; Padrón J. M.; Martin, V. S. J. Org. Chem. 2006, 71, 2339-2345; (f) Takahashi, S.; Kubota, A.; Nakata, T. Org. Lett. 2003, 5, 13531356; (g) Takahashi, S.; Ogawa, N.; Koshino, H.; Nakata, T. Org. Lett. 2005, 7, 2783-2786; (h) Takahashi, S.; Hongo, Y.; Ogawa, N.; Koshino, H.; Nakata, T. J. Org. Chem. 2006, 71, 6305-6308; (i) Takahashi, S.; Kubota, A.; Nakata, T. Tetrahedron 2003, 59, 1627-1638; (j) Evans, P. A.; Cui, J.; Gharpure, S. J.; Polosukhin, A.; Zhang, H.-R. J. Am. Chem. Soc. 2003, 125, 14702-14703; (k) Yoshimitsu, T.; Makino, T.; Nagaoka, H. J. Org. Chem. 2004, 69, 1993-1998.

6. Alali, F. Q.; Rogers, L. L.; Zhang, Y.; McLaughlin, J. L. Tetrahedron, 1998, 54, 5833-5844.

7. For a recent review of Pd-catalyzed cyclization: Muzart, J. Tetrahedron, 2005, 61, 5955-6008.

8. For Pd(II)-catalyzed diastereoselective formation of piperidine rings, see: (a) Yokoyama, H.; Otaya, K.; Kobayashi, H.; Miyazawa, M.; Yamaguchi, S.; Hirai, Y. Org. Lett. 2000, 2, 2427-2429; (b) Makabe, H.; Looi, K. K., Hirota, M. Org. Lett. 2003, 5, 27-29.

9. For a preliminary communication, Hattori, Y.; Furuhata, S.; Okajima, M.; Konno, H.; Abe, M.; Miyoshi, H.; Goto, T.; Makabe, H. Org. Lett., 2008, 10, 717-720.

10. Isolation: (a) Gleye, C:; Duret, P.; Laurens, A.; Hocquemiller, R.; Cavé, A. J. Nat. Prod. 1998, 61, 576-579. Synthesis and mitochondria complex I inhibitory activity: (b) Makabe, H.; Hattori, Y.; Kimura, Y.; Konno, H.; Abe, M.; Miyoshi, H.; Tanaka, A.; Oritani, T. Tetrahedron 2004, 60, 10651-10657.

11. Isolation: (a) McCloud, T. G.; Smith, D. L.; Chang, C. J.; Cassady, J. M. Experientia, 1987, 43, $947-949$. Mitochondria complex I inhibitory activity: ref. 1 (a).

12. Isolation: (a) Myint, S. H.; Laurens, A.; Hocquemiller, R.; Cavé, A.; Davoust, D.; Cortes, D. Heterocycles, 1990, 31, 861-867. Synthesis and mitochondria complex I inhibitory activity: (b) Hattori, Y.; Kimura, Y.; Moroda, A.; Konno, H.; Abe, M.; Miyoshi, H.; Goto, T.; Makabe, H. Chem. Asian, J. 2006, 1, 894-904.

13. Makabe, H.; Tanaka, A.; Oritani, T. Biosci. Biotechnol. Biochem. 1993, 57, 1028-1029.

14. Makabe, H. Biosci. Biotechnol. Biochem. 2007, 71, 2367-2374.

15. Negishi, E. In Handbook of Organopalladium Chemistry for Organic Synthesis., Ed.; Wiley-Interscience, 2002, Vol. 1, pp 43-45.

16. Becker, H.; Sharpless, K. B. Angew. Chem. 1996, 108, 447-449; Angew. Chem. Int. Ed. Engl. 1996, 35, 448451.

17. Han, H.; Shinha, M. K.; D’Souza, L. J.; Keinan, E.; Shinha, S. C. Chem. Eur. J. 2004, 10, 2149-2158.

18. Schaus, S. E.; Brandes, B. D.; Larrow, J. F.; Tokunaga, M.; Hansen, K. B.; Alexandra, E. G.; 
Furrow, M. E.; Jacobsen, E. N. J. Am. Chem. Soc. 2002, 124, 1307-1315.

19. Jiang, S.; Liu Z.-H.; Sheng, G.; Zeng, B.-B.; Cheng, X.-G.; Wu, Y.-L.; Yao, Z.-J. J. Org. Chem. 2002, 67, 3404-3408.

20. Yamaguchi, M.; Hirao, I. Tetrahedron Lett. 1983, 24, 391-394.

21. The molecular ratio of oxyrane 3 to: acetylene 2 was $1: 5$. In case of $1: 2$, the corresponding product was afforded in $30 \%$ yield.

22. Makabe, H.; Miyawaki, A.; Takahashi, R.; Hattori, Y.; Konno, H.; Abe, M.; Miyoshi, H. Tetrahedron Lett. 2004, 45, 973-977.

23. Sonogashira, K.; Tohda, Y.; Hagihara, N. Tetrahedron Lett. 1975, 16 , 4467-4470.

24. Makabe, H.; Kimura, Y.; Higuchi, M.; Konno, H.; Murai, M.; Miyoshi, H. Bioorg. Med. Chem. 2006, 14, 3119-3130.

25. The stereochemistry of the THF ring of cis-solamin was different from that of annonacin and murisolin. But Miyoshi and co-workers found that the stereochemistry around the THF ring(s) is of minor importance for the activity (ref. 1a and 12b). Thus, cis-solamin could be used for comparison.

26. Matsuno-Yagi, A.; Hatefi, Y. J. Biol. Chem. 1985, 260, 14424-14427. 